\title{
A Unique “Angiotensin-Sensitive” Neuronal Population Coordinates Neuroendocrine, Cardiovascular, and Behavioral Responses to Stress
}

\author{
๑DAnnette D. de Kloet, ${ }^{1 *}$ - $L e i$ Wang, ${ }^{2 *}$ Soledad Pitra, ${ }^{3}{ }^{-}$Helmut Hiller, ${ }^{2}$ Justin A. Smith, ${ }^{2}$ Yalun Tan, ${ }^{2}$ Dani Nguyen, ${ }^{2}$ \\ Karlena M. Cahill, ${ }^{2}{ }^{\mathbb{C}}$ Colin Sumners, ${ }^{1}$ Javier E. Stern, ${ }^{3}$ and Eric G. Krause ${ }^{2}$ \\ ${ }^{1}$ Department of Physiology and Functional Genomics, College of Medicine, and ${ }^{2}$ Department of Pharmacodynamics, College of Pharmacy, University of \\ Florida, Gainesville, Florida 32611, and ${ }^{3}$ Department of Physiology, Medical College of Georgia, Augusta University, Augusta, Georgia 30909
}

Stress elicits neuroendocrine, autonomic, and behavioral responses that mitigate homeostatic imbalance and ensure survival. However, chronic engagement of such responses promotes psychological, cardiovascular, and metabolic impairments. In recent years, the reninangiotensin system has emerged as a key mediator of stress responding and its related pathologies, but the neuronal circuits that orchestrate these interactions are not known. These studies combine the use of the Cre-recombinase/loxP system in mice with optogenetics to structurally and functionally characterize angiotensin type-1a receptor-containing neurons of the paraventricular nucleus of the hypothalamus, the goal being to determine the extent of their involvement in the regulation of stress responses. Initial studies use neuroanatomical techniques to reveal that angiotensin type-1a receptors are localized predominantly to the parvocellular neurosecretory neurons of the paraventricular nucleus of the hypothalamus. These neurons are almost exclusively glutamatergic and send dense projections to the exterior portion of the median eminence. Furthermore, these neurons largely express corticotrophin-releasing hormone or thyrotropin-releasing hormone and do not express arginine vasopressin or oxytocin. Functionally, optogenetic stimulation of these neurons promotes the activation of the hypothalamic-pituitary-adrenal and hypothalamic-pituitary-thyroid axes, as well as a rise in systolic blood pressure. When these neurons are optogenetically inhibited, the activity of these neuroendocrine axes are suppressed and anxiety-like behavior in the elevated plus maze is dampened. Collectively, these studies implicate this neuronal population in the integration and coordination of the physiological responses to stress and may therefore serve as a potential target for therapeutic intervention for stress-related pathology.

Key words: anxiety; cardiovascular; depression; glucocorticoids; hypertension; thyroid

\section{Significance Statement}

Chronic stress leads to an array of physiological responses that ultimately rouse psychological, cardiovascular, and metabolic impairments. As a consequence, there is an urgent need for the development of novel therapeutic approaches to prevent or dampen deleterious aspects of "stress." While the renin-angiotensin system has received some attention in this regard, the neural mechanisms by which this endocrine system may impact stress-related pathologies and consequently serve as targets for therapeutic intervention are not clear. The present studies provide substantial insight in this regard. That is, they reveal that a distinct population of angiotensin-sensitive neurons is integral to the coordination of stress responses. The implication is that this neuronal phenotype may serve as a target for stress-related disease.

\section{Introduction}

Stressors, real or perceived threats to homeostasis, elicit neuroendocrine, autonomic, and behavioral responses that mitigate the threats and ensure survival. Acutely, these responses are advantageous; however, chronic stress and the resulting implementation of these responses promotes a myriad of psychologi-
This work was supported by the following grants: National Institutes of Health (NIH) HL122494 (E.G.K.), NIH HL125805 (A.D.d.K.), NIH HL 033610 (C.S.), NIH HL112225 (J.E.S.). We thank David J. Pioquinto and Jacob A. Ludin for their technical assistance.

The authors declare no competing financial interests.

*A.D.d.K. and L.W. contributed equally to this work. 
cal, cardiovascular, and metabolic impairments. It is imperative that novel approaches to dampen the deleterious consequences of exaggerated "stress responses" be uncovered. This can be achieved by gaining a complete understanding of the mechanisms that regulate such responses. The paraventricular nucleus of the hypothalamus (PVN) lies at the heart of the stress response as it contains discrete populations of neurons that coordinate the physiological responses to stress. Identification of factors that affect the activity of specific neuronal phenotypes within the PVN may lead to novel therapeutic strategies for the alleviation of stress-related disease.

Accumulating evidence indicates that angiotensin receptor signaling within the brain can promote susceptibility or resiliency to stress-related disease (Krause et al., 2008, 2011; Pavlatou et al., 2008; Saavedra et al., 2011; Khoury et al., 2012; Saavedra, 2012; Marvar et al., 2014; Hurt et al., 2015; Nylocks et al., 2015; Wang et al., 2016a,b). Angiotensin-II (Ang-II) is the effector peptide of the renin-angiotensin system (RAS), an endocrine system best known for its role in hydromineral balance and cardiovascular function. However, both physiological and psychological stressors elicit its activation (Krause et al., 2008, 2011) and accumulating evidence indicates that Ang-II's actions at the angiotensin type-1a receptor (ATlaR) potentiate the intensity of stressresponding, but inhibition of ATlaRs reduces that intensity (Aguilera et al., 1995; Krause et al., 2008, 2011; Pavlatou et al., 2008; Saavedra et al., 2011; Wang et al., 2016b). In situ hybridization (ISH) and receptor binding revealed an abundance of AT1aRs within the PVN (Lenkei et al., 1997; Häuser et al., 1998). Consequently, the excitatory effects that brain-derived Ang-II has on stress-responding are thought to be mediated via its interaction with ATlaRs residing in the PVN.

The PVN contains microglia and astrocytes as well as a variety of neurosecretory and preautonomic neurons that control endocrine axes and sympathetic nervous system activity, respectively. While ATlaRs are known to influence neuroendocrine secretion (Aguilera et al., 1995) and sympathetic outflow (Li et al., 2003; Cato and Toney, 2005; Li and Pan, 2005; de Kloet et al., 2011), technical limitations that make it impossible to precisely locate AT1aRs in cells have so far prevented researchers from fully understanding how neurons that express AT1aRs within the PVN coordinate responses to stress (Benicky et al., 2012; Herrera et al., 2013). It has been proposed that AT1aRs are localized to neuronal (Aguilera et al., 1995; Oldfield et al., 2001; Wang et al., 2016b) and non-neuronal (Isegawa et al., 2014; Sun et al., 2015; Biancardi et al., 2016; Stern et al., 2016) phenotypes, but the identity of the cells within the PVN that express the ATlaR has not been definitively discerned. Furthermore, several lines of evidence have implicated the RAS as a prognosticator of stress-related disease (Pavlatou et al., 2008; Krause et al., 2011; Khoury et al., 2012; Saavedra, 2012; Wang et al., 2016b), but the mechanisms by which Ang-II and AT1aRs act within the PVN to coordinate neuroendocrine, autonomic, and behavioral responses to stress are unknown.

In this series of experiments, we sought to discern the neuroanatomical phenotype of AT1aR-containing cells within the PVN of mice by combining the Cre-lox system with recent advances in ISH. Subsequently, we used Cre-inducible adeno-associated virus (AAV)-mediated gene transfer of enhanced yellow fluores-

Correspondence should be addressed to Eric G. Krause, Assistant Professor, Department of Pharmacodynamics, College of Pharmacy, University of Florida, Gainesville, FL 32611. E-mail: ekrause@cop.ufl.edu.

DOI:10.1523/JNEUROSCI.3674-16.2017

Copyright $\odot 2017$ the authors $\quad 0270-6474 / 17 / 373479-13 \$ 15.00 / 0$ cent protein (eYFP) and light-sensitive ion channels [(channel-2 rhodopsin (ChR2) or step-waveform inhibitory channel rhodop$\sin$ (SwiChRca)] to determine the projection phenotype of ATlaR neurons and reveal the functional impact of optogenetically activating or inhibiting these PVN neurons under basal and stressful conditions. Collectively, our results indicate that neurons within the PVN that express ATlaRs can be manipulated to potently control the endocrine, autonomic, and behavioral limbs of the stress response.

\section{Materials and Methods}

Animals. All procedures were performed at the University of Florida (Gainesville, FL) or at Augusta University (Augusta, GA) were approved by the institutional animal care and use committees at these institutions and were conducted in accordance with the National Institutes of Health Guide for the Care and Use of Laboratory Animals. All male and female mice used in these studies were on a C57BL/6J background, were 8-10 weeks old at the initiation of the studies, and were maintained in temperature-controlled and humidity-controlled rooms on a 12:12 h light/dark cycle with food and water available ad libitum.

AT1aR-Cre knock-in mice were generated by Biocytogen and the University of Florida (Gainesville, FL). To express both Cre-recombinase and zsGreen without interrupting ATlaR expression, 2A-Cre-2AzsGreen was introduced upstream of ATlaR 3' UTR via homologous recombination (Fig. 1a). F1 heterozygous mice were bred with a FLPdeleter strain (Jackson Laboratory, stock \#011065), to excise the neomycin selection cassette and then back-crossed onto C57BL/6J for $\geq 2$ additional generations. ATlaR-Cre knock-in mice were used for AAVmediated gene transfer and subsequent anterograde neuronal tract tracing and optogenetics studies. AT1aR-Cre knock-in mice were also bred with stop-flox-tdTomato mice (Jackson Laboratories, stock \#007914) to verify and map Cre-recombinase expression throughout the PVNs of both male and female mice. These AT1aRCre $\times$ stop-flox-tdTomato mice are referred to as AT1aR-tdTomato mice throughout the manuscript.

Viral constructs. Viral vectors used for these studies were generated by and obtained from Dr. Karl Deisseroth and colleagues (Stanford University, Palo Alto, CA) or the Viral Vector Core at the University of North Carolina (Chapel Hill, NC). These AAV vectors (serotype-2) allow for the Creinducible expression of eYFP and also the light-sensitive ion channels (ChR2 or SwiChRca) and are as follows: for expression of eYFP and ChR2: pAAV2-EF1a-DIO-hChR2(H134R)-eYFP-WPRE (referred to as AAVChR2-eYFP); for the expression of eYFP and SwiChRca: AAV2-EF1aDIO-SwiChRca-TS-eYFP-WPRE (referred to as AAV-SwiChR2ca-eYFP); and for the expression of only eYFP: pAAV2-EF1a-DIO-eYFP (referred to as AAV-eYFP).

Stereotaxic surgery. Stereotaxic surgery was performed to deliver the retrograde tracer, FluoroGold (FG), to the rostral ventrolateral medulla (RVLM) or the Cre-inducible AAVs into the PVNs of ATlaR-tdTomato or ATlaR-Cre mice, respectively. In all cases, mice were anesthetized using isoflurane, administered analgesic (Buprenex; $0.1 \mathrm{mg} / \mathrm{kg}$ ) and prepared for stereotaxic surgery. For the retrograde neuronal tract tracing studies, male ATlaR-tdTomato mice received stereotaxic microiontophoretic injections of FG ( $6 \mu \mathrm{A}, 7 \mathrm{~s}$ pulses; $8 \mathrm{~min}$ ) into the RVLM (coordinates from lambda: $1.57 \mathrm{~mm}$ posterior, $\pm 1.3 \mathrm{~mm}$ lateral, and 5.07 $\mathrm{mm}$ ventral from the surface of the brain). Seven days after surgery, mice were anesthetized and perfused. Brain tissue was then processed for immunohistochemistry (IHC) as described below. For virally mediated gene transfer to the PVN, Cre-inducible AAVs described above were injected bilaterally into the PVNs of AT1aR-Cre mice using a picospritzer III (Parker) and the following coordinates from bregma: anteroposterior (AP), $\pm 0 \mathrm{~mm}$; mediolateral (ML), $\pm 0.25 \mathrm{~mm}$; dorsoventral (DV), -4.75 $\mathrm{mm}$. Pipettes were left in the PVN for $5 \mathrm{~min}$ to allow for diffusion of the AAVs (300-400 $\mathrm{nl}$ ) into the brain. Mice used for conscious, in vivo optogenetic studies, were then also stereotaxically implanted with a fiber optic post using the following coordinates from the bregma: AP, $\pm 0 \mathrm{~mm}$; ML, $\pm 0.25 \mathrm{~mm}$; DV,$-3.85 \mathrm{~mm}$. Mice used for anterograde tracing studies, in vitro electrophysiological studies, and in vivo (anesthetized) cardiovascular recordings were not implanted with the fiber optic posts 

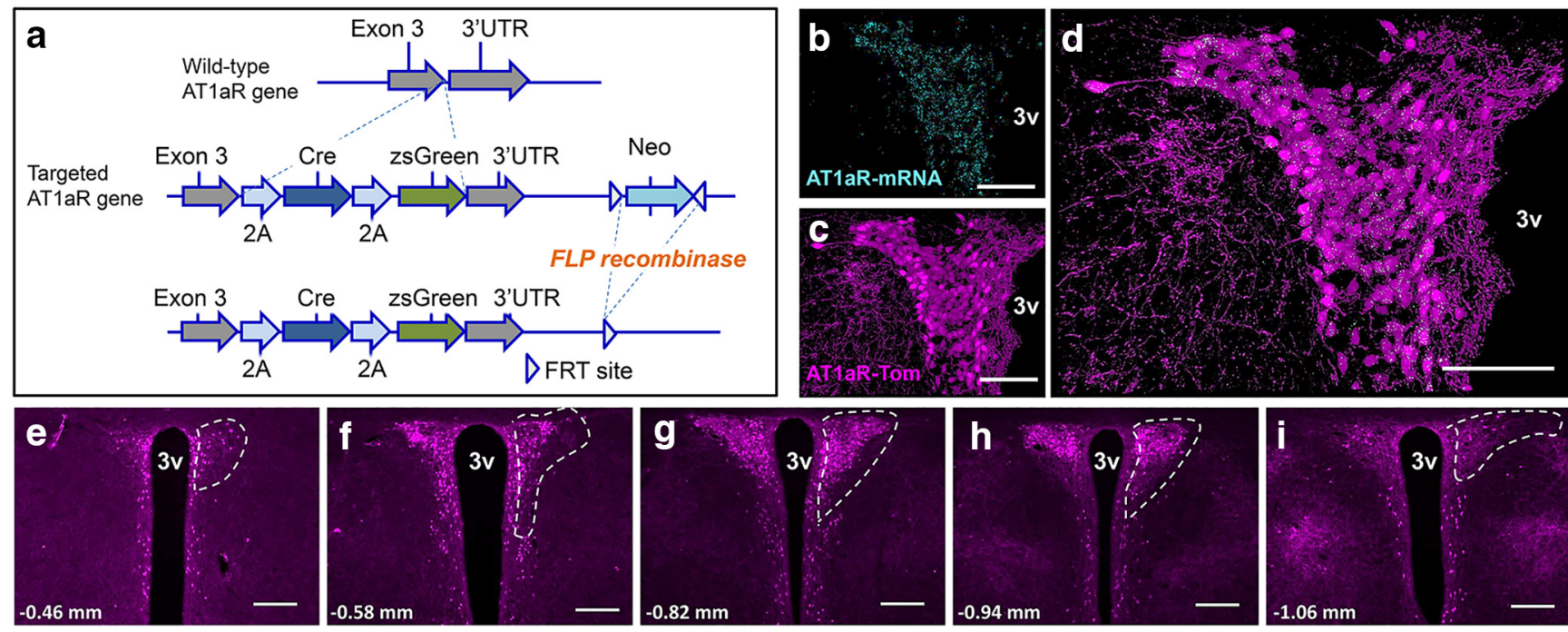

Figure 1. Validation of the AT1aR-Cre mouse line. $\boldsymbol{a}$, Top, Wild-type AT1aRgene. Middle, To express both Cre-recombinase and zsGreen without interrupting AT1aR expression, 2A-Cre-2A zsgreen was introduced upstream of AT1aR 3' UTR via homologous recombination. Bottom, F1 heterozygous mice were bred with a FLP-deleter strain, leading to the excision of the neomycin selection cassette. $\boldsymbol{b}$ - $\boldsymbol{d}$, Projection images of the PVN collected from a mouse expressing both the AT1aR-Cre and the td-Tomato-stop-flox reporter gene depicting (b) AT1aR mRNA in cyan, (c) AT1aRtdTomato-containing cells (AT1aR-Tom) in magenta, and (d) the merged image highlighting extensive overlap between the two markers. $\boldsymbol{g}$ - $\boldsymbol{i}, 10 \times$ images of coronal sections through the PVN of AT1aR-Tom reporter mice portraying (in magenta) the distribution of AT1aR-Tom throughout the PVN. White dashed lines outline the PVN unilaterally and the number on the bottom left of each image corresponds to the rostrocaudal distance from bregma. 3v, Third cerebral ventricle. Scale bars: $\boldsymbol{b}-\boldsymbol{d}, 100 \mu \mathrm{m} ; \boldsymbol{e}-\boldsymbol{i}, 200 \mu \mathrm{m}$.

during this procedure. All AAV-injected mice were allowed to recover for $\geq 2$ weeks before subsequent procedures.

Acute brain slice preparation. Hypothalamic brain slices were prepared according to methods previously described (Stern, 2001; Potapenko et al., 2011). Briefly, mice were anesthetized with pentobarbital $(50 \mathrm{mg} / \mathrm{kg}$, i.p.), brains were dissected out, and hypothalamic coronal slices (210 $\mu \mathrm{m})$ containing the PVN were cut in an oxygenated ice-cold artificial CSF (aCSF) containing the following (in $\mathrm{mm}$ ): $119 \mathrm{NaCl}, 2.5 \mathrm{KCl}, 1$ $\mathrm{MgSO}_{4}, 26 \mathrm{NaHCO}_{3}, 1.25 \mathrm{NaH}_{2} \mathrm{PO}_{4}, 20$ D-glucose, 0.4 ascorbic acid, 2 $\mathrm{CaCl}_{2}$, and 2 pyruvic acid, $\mathrm{pH} 7.3,295 \mathrm{mOsm}$. Slices were placed in a holding chamber containing aCSF and kept at room temperature until use.

Electrophysiology. Hypothalamic slices were transferred to a recording chamber and superfused with continuously bubbled $\left(95 \% \mathrm{O}_{2}, 5 \% \mathrm{CO}_{2}\right)$ $\operatorname{aCSF}\left(30-32^{\circ} \mathrm{C}\right.$ ) at a flow rate of $\sim 3.0 \mathrm{ml} / \mathrm{min}$. Thin-walled (outer diameter, $1.5 \mathrm{~mm}$; inner diameter, $1.17 \mathrm{~mm}$ ) borosilicate glass (G150TF-3, Warner Instruments) was used to pull patch pipettes (3-5 M $\Omega$ ) on a horizontal micropipette puller (P-97, Sutter Instruments). The internal solution contained the following (in $\mathrm{mM}$ ): 135 potassium gluconate, 0.2 EGTA, 10 HEPES, $10 \mathrm{KCl}, 0.9 \mathrm{MgCl}_{2}, 4 \mathrm{Mg}^{2+} \mathrm{ATP}, 0.3 \mathrm{Na}^{+} \mathrm{GTP}$, and 20 phosphocreatine $\left(\mathrm{Na}^{+}\right)$; $\mathrm{pH}$ was adjusted to $7.2-7.3$ with $\mathrm{KOH}$. Recordings were obtained from fluorescently labeled ATlaR-Cre-eYFP and ATlaR-tdTomato neurons with an Axopatch 200B amplifier (Molecular Devices), using a combination of fluorescence illumination and infrared differential interference contrast videomicroscopy. The voltage output was digitized at 16-bit resolution, $10 \mathrm{kHz}$, and was filtered at $2 \mathrm{kHz}$ (Digidata 1440A, Molecular Devices). Data were discarded if the series resistance was not stable throughout the entire recording $(>20 \%$ change; Stern, 2001; Potapenko et al., 2011). Drugs were pressure applied through a picospritzer pipette. Optogenetic manipulation of neuronal firing was achieved by delivering a blue light ( $488 \mathrm{~nm}$ laser) or green light (562 nm laser) to the slice using the Yokogawa real-time live-cell laser confocal system (CSU-10) combined with a highly sensitive EM CCD camera (iXon +885 , Andor Technology).

Assessment of neuroendocrine secretion in response to optogenetic manipulations. To test whether ATlaR-expressing neurons within the PVN regulate neuroendocrine secretion, we conducted in vivo optogenetic experiments in freely moving mice. Mice were administered the AAVs and implanted with fiber optic posts as described above, allowed to recover from the surgical procedure for 1 week, and then were habituated over 2 weeks to the handling and tethering procedures required for the blue-light stimulation (or inhibition) paradigm. After the habituation period, the mice underwent Test Day 1 followed either (1) by being killed for the collection of plasma to assess thyroid-stimulating hormone (TSH) and ACTH or (2) by a 1 week recovery period and then Test Day 2. Testing was performed during the light phase between 8:00 A.M. and 12:00 P.M.

On the day of the test, mice were brought into the procedure room, tethered to the light source, and then allowed to acclimate to the tether and procedure room for $90 \mathrm{~min}$ before the initiation of the blue-light stimulation/inhibition protocols. For mice that received the Creinducible AAV-ChR2-eYFP, the blue-light stimulation parameters were as follows and were sustained for a period of $15 \mathrm{~min}$ : $20 \mathrm{~ms}$ pulses, $15 \mathrm{~Hz}$, $5 \mathrm{~s}$ on followed by $5 \mathrm{~s}$ off. Fifteen minutes after the initiation of blue-light "stimulation," some mice were killed and their trunk blood was collected. For the others, tail blood was collected. For mice that received Cre-inducible AAV-SwiChRca-eYFP, the blue-light "inhibition" parameters were performed over $30 \mathrm{~min}$ and were as follows: $500 \mathrm{~ms}$ pulses, $0.033 \mathrm{~Hz}$. For these AAV-SwiChR2-eYFP mice, tail-blood sampling or killing and trunk-blood collection took place $30 \mathrm{~min}$ after the initiation of blue-light inhibition. For these mice, a tail-blood sampling procedure performed immediately before the initiation of the blue-light inhibition served as the mild stressor. Mice that were delivered the Cre-inducible control AAV-eYFP were handled as those that were delivered AAVChR2-eYFP. All mice were randomized to receive either the "Light on" condition or "Light off" condition on Test Day 1. In the cases where repeated sampling was possible [i.e., when assessing plasma corticosterone (CORT) or T4, which required lower volumes of plasma to assess], the opposite condition was delivered on Test Day 2. All blood samples were collected in $100 \mathrm{~mm}$ EDTA and then centrifuged at $6500 \mathrm{rpm}$ for 15 min at $4^{\circ} \mathrm{C}$. Plasma was extracted and stored at $-80^{\circ} \mathrm{C}$ for later analysis.

Assessment of blood pressure in response to optogenetic manipulations. To test whether ATlaR-expressing neurons within the PVN regulate blood pressure, in vivo optogenetic experiments were conducted in anesthetized animals. AT1aR-Cre mice were injected with Cre-inducible AAVs as described above. Six weeks after the injections of viruses, optogenetic experiments evaluated acute blood pressure responses to excitation or inhibition of AT1aR-expressing neurons within the PVN.

Blood pressure was measured using a Millar catheter (Model SPR 671, Millar) connected to a PowerLab signal transduction unit (ADInstruments) and was recorded and analyzed using Labchart software (ADInstruments). To measure blood pressure using a Millar catheter, mice 
were anesthetized using isoflurane and an incision $(\sim 1 \mathrm{~cm})$ was made on the midline of the ventral neck to expose the left carotid artery. Subsequently, a 1-cm-long segment of the carotid artery was separated from the vagus nerve using two sutures (size: 6-0); the cranial end of the segment was permanently ligated and the caudal end of the segment was temporally occluded. Next, the carotid artery was punctured using a 25 gauge bent needle and the catheter was slid into the artery lumen and then tied to the artery.

After catheterization, the head of the mouse was fixed on a stereotaxic instrument. Two holes were drilled on the skull using the coordinates from bregma: AP, $\pm 0 \mathrm{~mm}$; ML, $\pm 0.25 \mathrm{~mm}$. After drilling the holes, the mouse was given an intraperitoneal injection of $\alpha$-chloralose $(114 \mathrm{mg} /$ $\mathrm{kg}$ ) and then isoflurane was gradually decreased to 0 over a $30 \mathrm{~min}$ period. After complete withdrawal of isoflurane, a fiber optic post was placed into the PVN using the following coordinates from bregma: AP, $\pm 0 \mathrm{~mm} ; \mathrm{ML}, \pm 0.25 \mathrm{~mm} ; \mathrm{DV},-3.8 \mathrm{~mm}$. To test the effect of blue light on blood pressure, mice that received Cre-inducible AAV-eYFP or Creinducible AAV-ChR2-eYFP were stimulated with blue light for $60 \mathrm{~s}$ (20 ms pulses, $15 \mathrm{~Hz}, 5 \mathrm{~s}$ on followed by $5 \mathrm{~s}$ off) and mice that received AAV-SwiChRca-eYFP were stimulated with blue light for $180 \mathrm{~s}(500 \mathrm{~ms}$ pulses, $0.033 \mathrm{~Hz}$ ). If the mouse had altered blood pressure in response to blue light and the blood pressure eventually recovered to basal levels after light exposure, then the stimulation or inhibition protocol was repeated $\geq 2$ additional times. A response was determined to be real only when it was reproduced $\geq 3$ times. Blood pressure data for each session of bluelight stimulation/inhibition were recorded starting from $30 \mathrm{~s}$ before the onset of blue light until the blood pressure returned to the prestimulation level. Blood pressure data were condensed into $5 \mathrm{~s}$ bins for each stimulation session. Three stimulation sessions were collected from each mouse and all the datasets were averaged to generate curves representing the systolic blood pressure responses to blue light in mice receiving each AAV.

Assessment of anxiety-like behavior in response to optogenetic manipulations. Anxiety-like behavior was assessed during the light phase (between 8:00 A.M. and 12:00 P.M.) using an elevated plus maze (EPM) that consists of two opposing closed arms and two opposing open arms $(31 \times$ $6 \mathrm{~cm}$ for each arm) elevated $41 \mathrm{~cm}$ above the floor. As described above, mice that underwent stereotaxic surgery to deliver the AAVs and implant the fiber optics into the PVN were allowed 1 week to recover from the surgical procedure and were then habituated to the tethering procedure over a period of 2 weeks. On the day of the test, mice were brought into the testing room and again habituated to the tether in their home cage for 5 min. Mice were then placed in the center of the EPM and allowed to explore the maze for a period of $5 \mathrm{~min}$. In all cases, mice were randomized to either receive the blue-light stimulation protocol (Light on) or no light (Light off). For the AAV-ChR2-eYFP and the AAV-eYFP mice, the bluelight stimulation parameters were as follows: $20 \mathrm{~ms}$ pulses, $15 \mathrm{~Hz}, 5 \mathrm{~s}$ on followed by $5 \mathrm{~s}$ off. For the $A A V$-SwiChR 2 mice, the stimulation parameters were $500 \mathrm{~ms}$ pulses at $0.033 \mathrm{~Hz}$. Light-stimulation protocols continued for the entirety of the $5 \mathrm{~min}$ test. Testing sessions were recorded by a ceiling-mounted video camera connected to a PC running TopScan software (CleverSystem), which allowed for analysis of the mouse behavior in real time.

Tissue collection and sectioning. Mice were anesthetized with pentobarbital and perfused transcardially with $0.15 \mathrm{M} \mathrm{NaCl}$ followed by $4 \%$ paraformaldehyde. Brains were then postfixed for 3-4 h, after which they were stored in $30 \%$ sucrose until sectioned using a Leica CM3050 S cryostat (Leica). For ISH experiments, perfused mouse brains were sectioned at $20 \mu \mathrm{m}$ into six serial sections and immediately mounted onto SuperFrost Plus Gold microscope slides. After air drying at room temperature for $20-30 \mathrm{~min}$, slides were stored at $-80^{\circ} \mathrm{C}$ until further processing. All solutions were prepared with DEPC-treated water and filtered using a $0.22 \mu \mathrm{m}$ filter. Tissue collection and sectioning were performed in RNase-free conditions. For IHC studies, mouse brains were sectioned at $30 \mu \mathrm{m}$ into four serial sections and stored in cryoprotective solution at $-20^{\circ} \mathrm{C}$ until further processing.

IHC. The IHC protocols required for these studies are described in de Kloet et al. (2016). In brief, brain sections were removed from cryoprotectant solution and rinsed five times for $5 \mathrm{~min}$ each in $50 \mathrm{~mm}$ potassium
PBS (KPBS). Sections were then incubated first in blocking solution ( $2 \%$ normal donkey serum and $0.2 \%$ Triton X-100 in $50 \mathrm{~mm} \mathrm{KPBS}$ ) for $2 \mathrm{~h}$ at $25^{\circ} \mathrm{C}$ and then in the primary antibody (diluted in blocking solution) for $18 \mathrm{~h}$ at $4^{\circ} \mathrm{C}$. Sections were again rinsed five times for 5 min each before incubation in the secondary antibody (also diluted in blocking solution) for $2 \mathrm{~h}$ at $25^{\circ} \mathrm{C}$. After a final series of rinses, sections were mounted onto slides, allowed to air dry and then coverslipped using polyvinyl alcohol mounting medium. All primary antibodies were characterized by the manufacturers and in previously published studies (Ben-Barak et al., 1985; Jessberger et al., 2008; Kádár et al., 2010; Dimitrov et al., 2013). These antibodies and dilutions used are as follows: green fluorescent protein (Life Technologies, A10262; 1:1000), oxytocin-neurophysin [OT; Dr. H. Gainer, National Institutes of Health (NIH); PS-38; 1:400], vasopressin-neurophysin (AVP; Dr. H. Gainer, NIH; PS-4; 1:400), FG (Millipore, AB153; 1:1000) and c-fos (Santa Cruz Biotechnology, sc52). All secondary antibodies were purchased from Jackson Immunoresearch, raised in donkey, and used at a 1:500 dilution. Importantly, qualitative IHC studies were performed in $\geq 4$ separate mice.

RNAscope ISH. RNAscope ISH was performed as per the manufacturer's instructions and as previously described (de Kloet et al., 2016). To validate the use of the ATlaR in the ISH probe, ATlaR mRNA was examined and not observed in the PVN AT1aR knock-out mouse described in de Kloet et al. (2013; data not shown).

Image capture and processing. Images were captured and processed using Axiovision 4.8.2 software and a Zeiss AxioImager fluorescent Apotome microscope. For IHC studies, images were captured at $5 \times$ and $z$ stacks were captured at $20 \times$. For dual IHC/RNAscope ISH, $z$ stacks of the proteins and transcripts of interest were captured at $20 \times$ magnification throughout the ROIs using neuroanatomical landmarks found in a mouse brain atlas (Franklin and Paxinos, 2008). In all cases, $z$ steps were set at $0.5 \mu \mathrm{m}$, with an average of 20 optical sections per image. These $z$ stacks were used to generate the projection images depicted throughout the manuscript. For each experiment, sections hybridized with the positive control probes were used to determine the exposure time and image processing required to provide optimal visualization of RNA signal. As described in detail by de Kloet et al. (2016), these same parameters were then used for visualization of mRNA transcripts of interest, to assess background fluorescence in sections hybridized with negative control probe (DapB), and to determine the specificity of the probes using tissue obtained from knock-out mice. Importantly, using these exposure times and image-processing parameters there was minimal or no fluorescence in sections hybridized with the negative control probe and in sections obtained from knock-out mice. All final figures were then prepared using Adobe Photoshop 7.0 where the brightness and contrast was adjusted to provide optimal visualization.

Plasma hormone levels. CORT levels in samples collected from in vivo optogenetic studies were assessed using a ${ }^{125} \mathrm{I}$ radioimmunoassay (RIA) kit from MP Biomedicals as described by Krause et al. (2008) and de Kloet et al. (2009). Plasma ACTH was measured by RIA using an antiserum donated by Dr. William Engeland (Jasper and Engeland, 1991; University of Minnesota, Minneapolis, MN) and ${ }^{125} \mathrm{I}$-ACTH as tracer (PerkinElmer). Plasma T4 was assessed using a commercially available mouse/rat T4 total ELISA kit (Calbiotech) following the manufacturer's protocol. Plasma TSH levels were assessed via RIA by Dr. Samuel Refetoff (University of Chicago) using a sensitive, heterologous, disequilibrium, double-antibody precipitation RIA that has been previously described (Pohlenz et al., 1999).

Statistics. For studies evaluating the impact of blue-light stimulation/ inhibition on plasma hormone levels, statistical significance was determined using $t$ tests comparing the Light-on to the Light-off condition for each AAV. For CORT and T4 levels, a within-subjects design was used and these data were then expressed as a percentage of the corresponding Light-off values. A between-subjects design was needed because of the relatively larger plasma sample size for the ACTH and TSH assays, which required the killing of mice. The raw values are reported for these data. Systolic blood pressure values are reported as change from the baseline (Light-off) condition for each mouse, and statistical significance was ascertained via two-way ANOVA and subsequent Bonferroni's post hoc analyses. Finally, anxiety-like behavior (relative to the Light-off condi- 
tions) was evaluated using a between-subjects design and $t$ tests comparing the Light-off to Light-on values for each AAV. In all cases, $p<$ 0.05 was considered statistically significant.

\section{Results}

AT1aR-Cre validation and distribution in the paraventricular nucleus of the hypothalamus

Initial experiments assessed the validity of the newly developed AT1aR-Cre mice (Fig. 1) for use in subsequent studies interrogating the structure and function of ATlaR-containing cells within the PVN. To efficiently visualize Cre-containing cells, the AT1aR-Cre mice were bred to stop-flox-tdTomato mice, leading to offspring in which red fluorescent protein was expressed in all cells that contain Cre (i.e., AT1aR-tdTomato mice). Figure $1 b-d$ depicts the localization of ATlaR mRNA to the fluorescent ATlaRtdTomato neurons within the PVN. Importantly, $97.1 \pm 0.87 \%$ of the neurons that fluoresced red also contained detectable ATlaR mRNA, and sparse ATlaR mRNA was observed in the nontdTomato neurons within the PVN $(\sim 1.55 \pm 0.25 \%$ non-tdTomato neurons that labeled for the neuronal marker $\mathrm{HuC/D}$ in the PVN express detectable ATlaR mRNA). Moreover, there was extensive overlap in the localization of ATlaR mRNA and Cre-recombinase mRNA to neurons in the PVN of an AT1a-Cre mouse, further corroborating the validity of this mouse line (data not shown).

The rostral-caudal distribution of the ATlaR throughout the PVN is depicted in Figure $1 e-i$, which includes representative low-power images of coronal sections throughout the PVN of the AT1aR-tdTomato mouse. Analysis of these images revealed a high density of the AT1aR-tdTomato neurons within the parvocellular neurosecretory subdivision. Interestingly, the parvocellular preautonomic portion of the PVN, which has been hypothesized to contain ATlaR (Li et al., 2003; Cato and Toney, 2005; Li and Pan, 2005), contains only sparse ATlaR-tdTomato cell bodies.

Ang-II excites AT1aR-tdTomato neurons in the paraventricular nucleus of the hypothalamus

Patch-clamp electrophysiological studies were then conducted to determine the impact of Ang-II application on the activity of these neurons (Fig. $2 a-c$ ). Figure $2 d$, displays representative electrophysiological traces, indicating that focal Ang-II (100 and 500 $\mu \mathrm{M})$ application leads to the generation of action potentials in all neurons tested $(n=6)$. These action potentials are effectively prevented by the pretreatment of the brain slice with the AT1R antagonist losartan $(10 \mu \mathrm{M} ; n=3)$.

The AT1aR-tdTomato neurons of the paraventricular nucleus of the hypothalamus are activated by restraint stress

Due to the known role of the parvocellular PVN in the initiation of stress responses, we next assessed the impact of an acute psychological stressor on the activation of the ATlaR-tdTomato neurons of the PVN. This was accomplished by conducting IHC for Fos, a marker of neuronal activation, on coronal sections through the PVN collected from unhandled control mice or mice subjected to an acute restraint challenge. Representative images from this analysis, included in Figure 3, reveal that while there were essentially no AT1aR-tdTomato neurons expressing Fos in the control condition (Fig. 3a), there was robust activation in the stressed condition (Fig. $3 b$ ). In particular, $37.2 \pm 0.83 \%$ of AT1aR-tdTomato neurons were activated in response to the stressor, while $0.0 \pm 0.1 \%$ were activated in the unhandled control condition.

\section{The AT1aR is expressed on parvocellular neurosecretory neurons within the paraventricular nucleus of the hypothalamus}

An important objective of this study was to determine the phenotype of ATlaR-tdTomato cells within the PVN. Based on the morphology and distribution of AT1aR-tdTomato cells within the PVN, we hypothesized that these cells were mostly parvocellular neurons and that they would be colocalized with both corticotropin-releasing hormone (CRH) and thyrotropinreleasing hormone (TRH) mRNAs. Consistent with this hypothesis, Figure $4 a-d$ depicts extensive localization of CRH mRNA and TRH mRNA to ATlaR-tdTomato neurons. Quantification of the dual ISH/IHC studies revealed that $48.7 \pm 1.78 \%$ of ATlaR-tdTomato neurons in males contained CRH mRNA and $22.4 \pm 1.40 \%$ contained TRH mRNA. Females similarly displayed extensive localization of CRH mRNA and TRH mRNA to ATlaR-tdTomato neurons. That is, $60.3 \pm 5.63 \%$ of ATlaRtdTomato neurons in females contained CRH mRNA, while $26.4 \pm 1.78 \%$ contained TRH mRNA.

Furthermore, both CRH and TRH neurons are generally glutamatergic (i.e., they express vGlut2 mRNA within the PVN; Hrabovszky et al., 2005) and in the present study, nearly all AT1aR- 

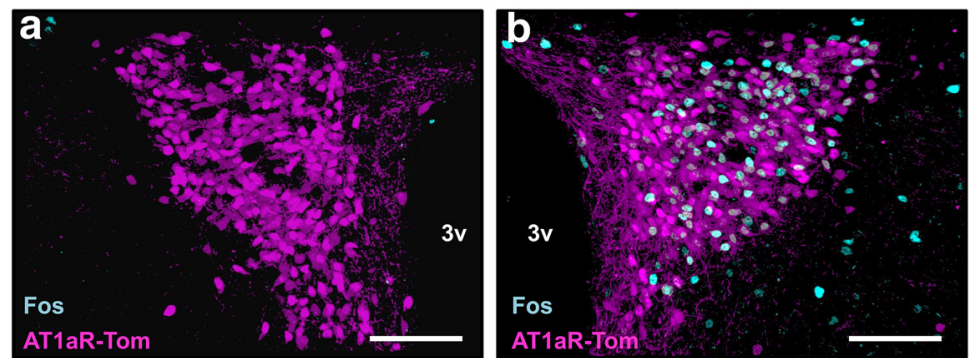

Figure 3. AT1aR-tdTomato neurons are activated by restraint stress. $\boldsymbol{a}, \boldsymbol{b}$, Representative projection images through the PVN of AT1aR-tdTomato reporter mice under $(\boldsymbol{a})$ nonstressed control conditions or $(\boldsymbol{b})$ subsequent to an acute restraint stress challenge. AT1aR-tdTomato is depicted in magenta and Fos (a marker of neuronal activation) is depicted in cyan. 3v, Third ventricle. Scale bars, $100 \mu \mathrm{m}$.

tdTomato neurons within the PVN contained vGlut 2 mRNA (94.7 $\pm 0.82 \%$; Fig. $4 e-g$ ). Conversely, no overlap was observed between ATlaR-tdTomato and AVP (Fig. 4h-j) or OT (Fig. 4k-m) immunoreactivity, nor was there any overlap between ATlaRtdTomato and nucleus tractus solitarius-projecting or preautonomic, RVLM-projecting FG neurons (Fig. $4 n-p$ ). Despite, the apparent lack of ATlaR-tdTomato to preautonomic RVLMprojecting neurons, ATlaR-tdTomato fibers and/or terminals are densely localized to this portion of the PVN and come into close contact with the RVLM-projecting preautonomic neurons of the region (Fig. $4 q-v$ ).

\section{Mapping of AT1aR projections from the paraventricular nucleus of the hypothalamus}

To map the projections of ATlaR-containing neurons of the PVN, AAV-ChR2-eYFP was delivered into the PVN of AT1aRCre mice (Fig. 5a-i). The viral construct used for the delivery of the dual lox-flanked and inverted ChR2 and eYFP sequences is depicted in Figure $5 a$. Administration of this AAV into the PVN of the AT1aR-Cre mice led to the expression of eYFP and ChR2 only in the Cre-containing ATlaR neurons of the PVN, thereby allowing for the mapping of PVN-AT1aR projections and subsequent optogenetic analysis of the function.

The specific transfer of eYFP to PVN neurons can be observed in Figure $5 b$, which depicts a mosaic of low-power images throughout the entirety of a coronal section obtained from a representative mouse used for these studies. Figure $5 c-f$ highlights the dense projections extending ventrolaterally from the PVN, presumably toward the median eminence. Consistent with this, Figure $5 g, h$ indicates the dense localization of eYFP fibers within the median eminence, particularly to $\mathrm{CRH}$-containing nerves terminals within the area. Further analysis of AT1aR-tdTomato fibers/terminals was limited primarily to regions known to receive projections from the PVN. Fibers were observed in many hypothalamic brain regions, such as the arcuate and ventromedial nuclei, and sparse fibers were observed in a few other regions, including the subfornical organ. Of relevance, most hypothalamic brain regions that contain eYFP fibers in this study are also known to contain fibers of passage from the PVN to the median eminence. Finally, and consistent with the retrograde tract tracing studies conducted in the previous section, no fibers/terminals were observed in the ventrolateral medulla (VLM) area (data not shown), suggesting again that PVN ATlaR neurons do not themselves project to the VLM.

Functional impact of in vitro optogenetic manipulations of paraventricular nucleus of the hypothalamus AT1aR neurons Patch-clamp electrophysiological studies were then conducted to determine the impact of the optogenetic stimulation or inhibi- tion of these neurons in vitro. Brain slices were obtained from ATlaR-Cre mice delivered the viral constructs described in Figure $6 a$ into the PVNs, and were allowed to recover for 2-4 weeks before conducting the in vitro electrophysiological assessments (Fig. 6b). Recordings obtained from AAV-ChR2-eYFP PVN neurons $(n=6)$ showed that they displayed general membrane properties characteristic of parvocellular neurosecretory neurons, including lack of a transient outward rectification and a small or absent lowthreshold spike, following a series of depolarizing current steps (Fig. $6 c$; Luther and Tasker, 2000; Luther et al., 2002). As shown in Figure $6 d-f$, optogenetic stimulation with varying protocols of $488 \mathrm{~nm}$ laser pulses reliably evoked firing of single action potentials or bursts of multiple action potentials in the patched neurons. Moreover, recordings obtained from AAV-SwiChRca-eYFP neurons $(n=5)$ demonstrate that by using a combination of 488 and $562 \mathrm{~nm}$ laser pulses we can reliably inhibit their firing activity, either in a transient or sustained manner (Fig. $6 g-i$ ). Together, these in vitro studies support the functional efficacy of the virus delivery of the ChR2 and SwiChRca constructs, and their ability to efficiently stimulate or inhibit the activity of AT1aR-expressing PVN neurons, respectively.

The contribution of AT1aR neurons in the paraventricular nucleus of the hypothalamus to neuroendocrine secretion

The initial studies describing the structure of ATlaR-containing cells within the PVN allowed for the generation of hypotheses regarding the function of these neurons in vivo. Within the PVN, the AT1aR was primarily expressed on CRH and TRH neurons, and consequently, we hypothesized that the hypothalamicpituitary-adrenal (HPA) and the hypothalamic-pituitarythyroid (HPT) axes would both be activated upon blue-light stimulation of these neurons. To test this hypothesis, AT1aRCre mice were delivered the AAVs included in Figure $6 a$, habituated to the tethering protocol, and then put through optogenetic testing as described in Materials and Methods and in Figure $7 a$. A coronal section through a representative "hit" used for these studies is depicted in Figure $7 b$. Stimulation/ inhibition of AT1aR neurons using the test protocol depicted in Figure $7 c$ and stimulation/inhibition parameters based on those used in vitro led to alterations in the circulating levels of ACTH (Fig. 7d), CORT (Fig. 7e), TSH (Fig. 7f), and T4 (Fig. $7 g$ ) that are consistent with these neurons having an excitatory influence over the HPA and HPT axes. Specifically, blue-light stimulation of AT1aR-expressing neurons within the PVN significantly elevated the baseline (nonstressed) levels of ACTH $\left(p=0.048 ; t_{(6)}=2.47\right), \operatorname{CORT}\left(p<0.0001 ; t_{(23)}=15.6\right), \mathrm{TSH}$ $\left(p=0.0002 ; t_{(13)}=5.03\right)$, and T4 $\left(p=0.03 ; t_{(8)}=2.64\right)$ relative to the Light-off condition. Conversely, the inhibition of these neurons led to a significant reduction in both the CORT $\left(p=0.013 ; t_{(11)}=2.94\right)$ and TSH $(p=0.02$; $\left.t_{(16)}=2.59\right)$ responses to the tail blood-collection procedure (i.e., the stressor). There were no differences between the Light-on (stimulation/inhibition) and Light-off values for any of these hormones in mice that were delivered the control virus. 

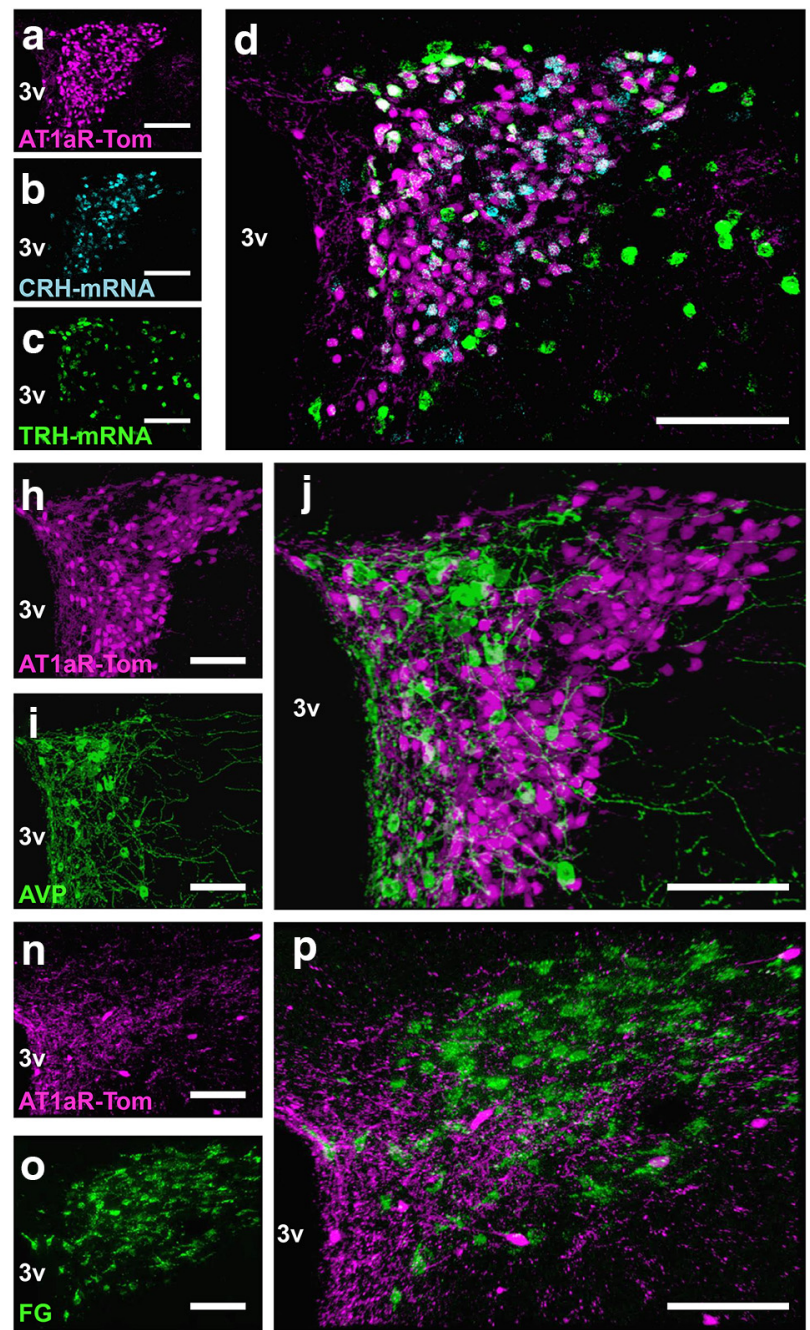
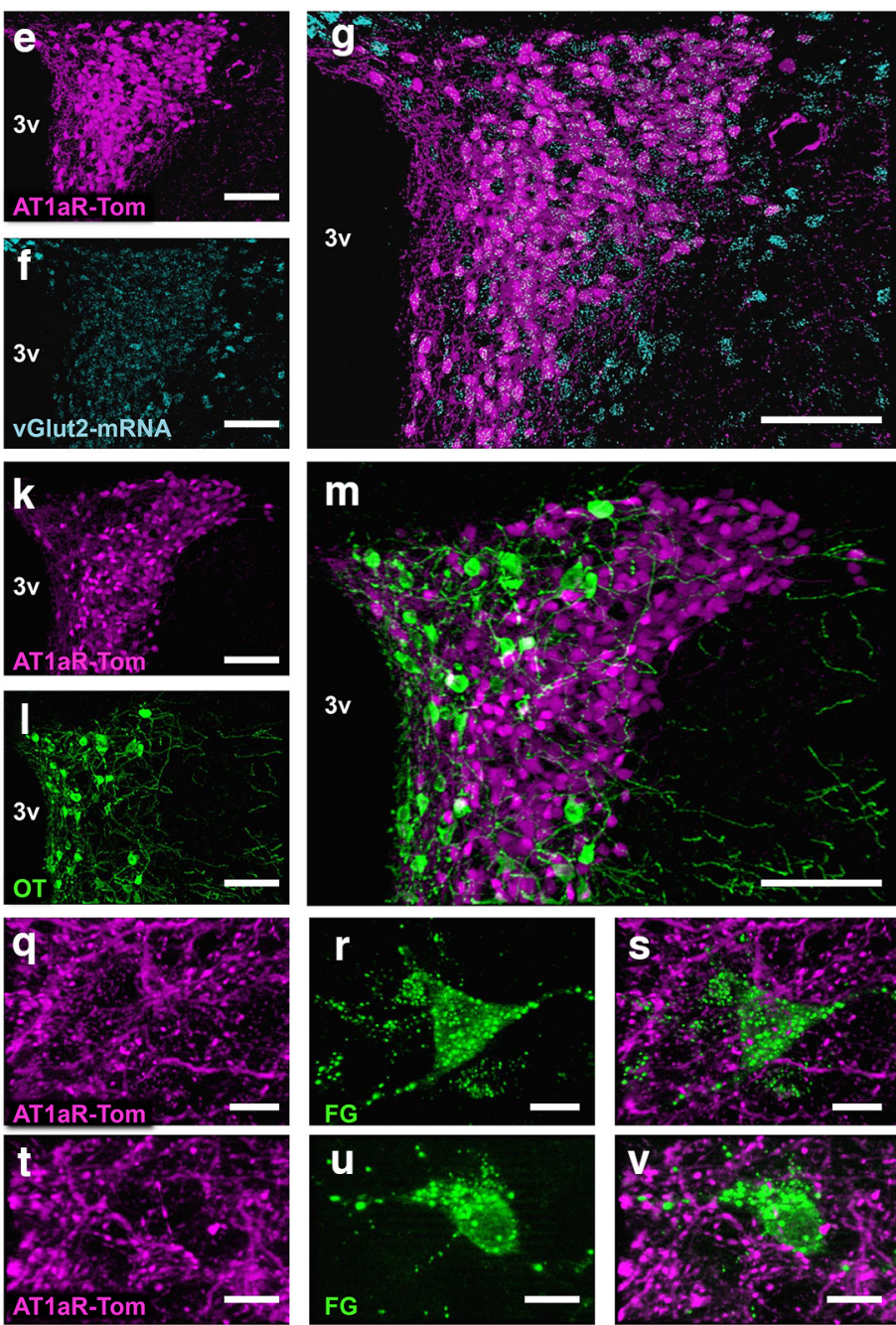

Figure 4. Neurochemical phenotype of AT1aR-containing cells within the PVN. $\boldsymbol{a}-\boldsymbol{m}$, Coronal sections through the PVN of an AT1aR-tdTomato reporter mouse depicting tdTomato and either $(\boldsymbol{a}-\boldsymbol{d})$ CRH and TRH mRNA, $(\boldsymbol{e}-\boldsymbol{g})$ vGlut2 mRNA, $(\boldsymbol{h}-\boldsymbol{j})$ AVP, $(\boldsymbol{k}-\boldsymbol{m})$ OT, or $(\boldsymbol{h}-\boldsymbol{j})$ FG-labeled rostral ventrolateral medulla-projecting preautonomic neurons. $\boldsymbol{a}-\boldsymbol{d}$, Projection images of the PVN depicting ( $\boldsymbol{a}$ ) AT1a-Tom in magenta, ( $\boldsymbol{b})$ CRH mRNA in cyan, (c) TRH mRNA in green, and (d) the merged image. $\boldsymbol{e}-\boldsymbol{g}$, Projection images of the PVN depicting $(\boldsymbol{e})$ AT1a-Tom in magenta, $(\boldsymbol{f})$ vGlut2 mRNA in cyan, and $(\boldsymbol{g})$ the merged image. $\boldsymbol{h}-\boldsymbol{j}$, Projection images of the PVN depicting $(\boldsymbol{h})$ AT1a-Tom in magenta, $(\boldsymbol{i})$ AVP in green, and $(\boldsymbol{j})$ the merged image. $\boldsymbol{k}-\boldsymbol{m}$, Projection images of the PVN depicting $(\boldsymbol{k})$ AT1a-Tom in magenta, $(\boldsymbol{I})$ OT in green, and $(\boldsymbol{m})$ the merged image. $\boldsymbol{n}-\boldsymbol{p}$, Projection images of the PVN collected from AT1aR-tdTomato mice that received FG injections into the RVLM and were perfused 7 d later depicting $(\boldsymbol{n}, \boldsymbol{q}, \boldsymbol{t})$ AT1aR in magenta, $(\boldsymbol{o}, \boldsymbol{r}, \boldsymbol{u})$ FG-labeled RVLM-projecting neurons in green, and ( $\boldsymbol{p}, \boldsymbol{s}, \boldsymbol{v})$ the merged images. 3v, Third cerebral ventricle. Scale bars: $\boldsymbol{a}-\boldsymbol{p}$, $100 \mu \mathrm{m} ; \boldsymbol{q}-\boldsymbol{v}, 10 \mu \mathrm{m}$.

Optical stimulation of AT1aR neurons in the paraventricular nucleus of the hypothalamus increases blood pressure

We then conducted in vivo optogenetic experiments in anesthetized AT1aR-Cre mice to determine whether ATlaR-expressing neurons within the PVN regulate blood pressure. As highlighted in Figure 8, the blue-light stimulation protocol led to a significant elevation in systolic blood pressure in mice injected with AAVChR2-eYFP, while it had no impact on the systolic blood pressures of mice that received the Cre-inducible AAV-eYFP or AAV-SwiChRca-eYFP. That is, there were main effects of time $\left(p<0.0001, F_{(45,1620)}=7.93\right)$ and AAV group $(p<0.0001$, $\left.F_{(2,36)}=13.42\right)$, as well as a significant interaction between the two $\left(p<0.0001, F_{(90,1620)}=8.52\right)$. Post hoc analysis revealed that the systolic blood pressure of the AAV-ChR2-eYFP group was significantly elevated compared with the control AAVeYFP group for all time points between 25 and $115 \mathrm{~s}$ after the onset of the blue-light stimulation protocol $(p<0.05)$. It is important to acknowledge here that, although we expect to obtain similar results in unanaesthetized mice, this may not necessarily be the case. Therefore, future studies should examine cardiovascular parameters in awake mice subjected to blue-light stimulation/inhibition.

Inhibition of AT1aR neurons in the paraventricular nucleus of the hypothalamus attenuates anxiety-like behavior

Final experiments evaluated the behavioral impact of the inhibition/stimulation of these neurons using the EPM. The data included in Figure 9, demonstrate that inhibition of these PVN ATlaR neurons by the blue light in mice delivered AAVSwiChRca-eYFP significantly increases the percentage of time that mice spend in the open arms of the maze relative to the Light-off controls $\left(p=0.03 ; t_{(12)}=2.457\right)$. The implication is that inhibition of AT1aR neurons in the PVN is anxiolytic. Conversely, the blue-light stimulation protocol did not alter openarm time for the AAV-eYFP controls or for the AAV-ChR2-eYFP mice. Furthermore, total distance traveled was not altered by the blue-light stimulation protocol in any of the conditions. 
a
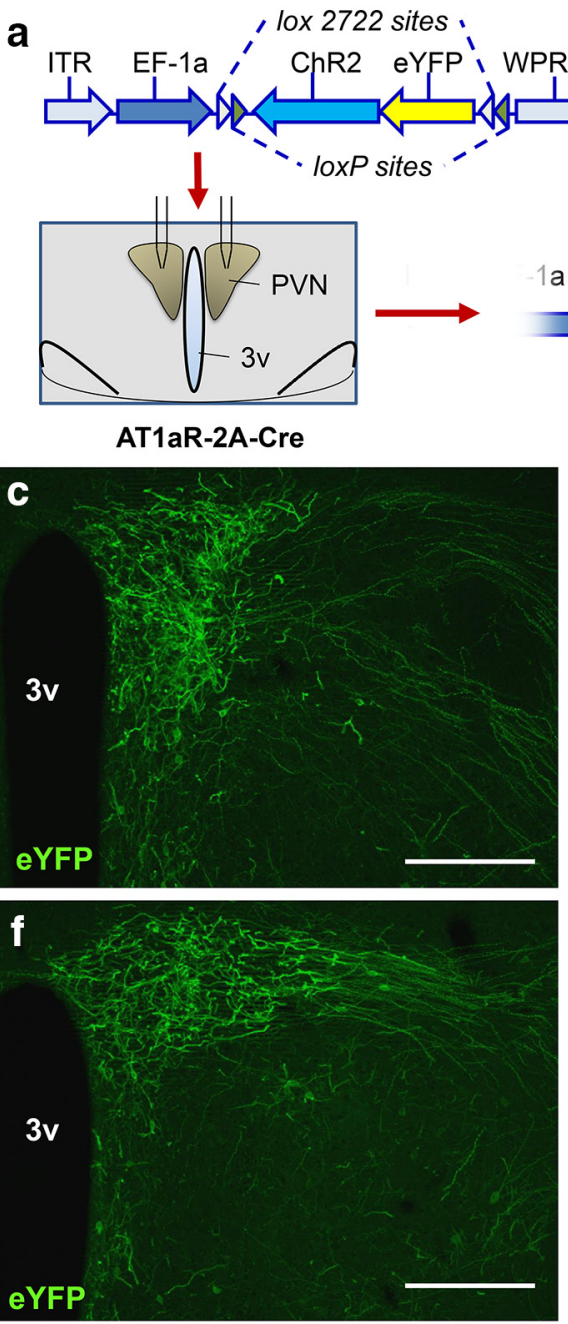

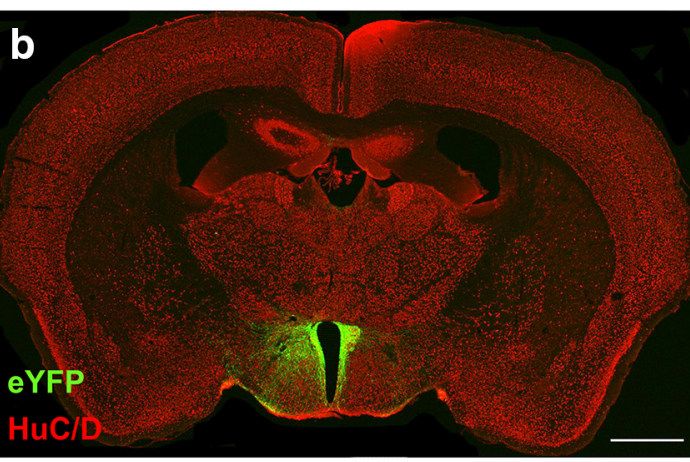

PVN AT1aR cells
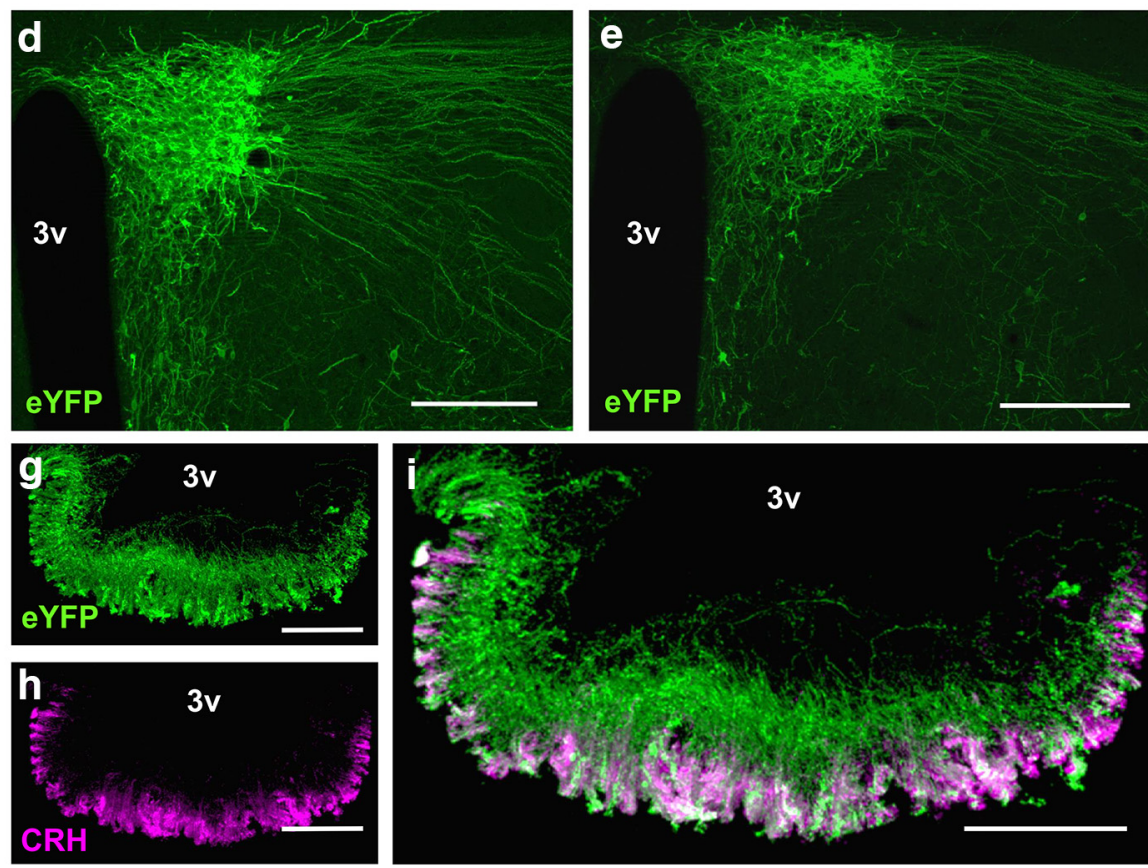

Figure 5. AT1aR-Cre neurons project primarily to the median eminence. $\boldsymbol{a}$, Schematic illustrating (1) the viral construct used to direct the Cre-dependent expression of ChR2 and eYFP to neurons within the PVN of the AT1aR-Cre mouse, (2) the bilateral injection of the AAV into the PVN, and (3) the subsequent Cre-mediated inversion of the dual floxed eYFP and ChR2 into the correct orientation. $\boldsymbol{b}$, Coronal section through the PVN of a representative "hit" used for the neuroanatomical studies highlighting the specific localization of eYFP (green) to the neurons (HuC/D, labeled in red) of PVN of the AT1aR-Cre mouse and not to adjacent brain nuclei. c $\boldsymbol{c}$, Higher-magnification images of the PVN of such a representative hit underscoring again the specificity of the injection and also depicting the ventrolateral projection of the eYFP fibers. $\boldsymbol{g}$, Dual-label IHC for eYFP and CRH in an AT1aR-Cre mouse that received the AAV-ChR2-eYFP into the PVN. 3v, Third cerebral ventricle. Scale bars: $\boldsymbol{b}, 1 \mu \mathrm{m} ; \boldsymbol{c}-\boldsymbol{f}, 200 \mu \mathrm{m} ; \boldsymbol{g}-\boldsymbol{i}, 100 \mu \mathrm{m}$.

\section{Discussion}

Decades of research have led to an appreciation of ATlaR expression within the PVN, and to hypothesize roles for this population of AT1aRs in stress-related disease. Along these lines, AT1aRs are implicated in the cardiovascular, behavioral, and neuroendocrine responses to physiological and psychological stressors and have been considered as therapeutic targets for a number of stress-related disorders (Krause et al., 2008, 2011; Pavlatou et al., 2008; Saavedra et al., 2011; Khoury et al., 2012; Saavedra, 2012; Marvar et al., 2014; Hurt et al., 2015; Nylocks et al., 2015; Wang et al., 2016b). However, there has been much debate on the mechanisms underlying the influence of ATlaRs over these responses and the extent to which PVN ATlaRs are involved in the genesis of stress-related pathology is not clear. These uncertainties are due to an incomplete understanding of the neurochemical phenotype of ATlaR-containing cells within the brain, particularly in the PVN, and have been remedied in the present study by implementation of the Cre/lox system and optogenetic approaches that characterize PVN ATlaR neurons. The present set of studies reveal that AT1aRs are localized predominantly to par- vocellular neurosecretory $\mathrm{CRH}$ and TRH neurons and that activation or inhibition of these PVN ATlaR-containing neurons profoundly impacts neuroendocrine secretion, blood pressure, and anxiety-like behavior.

An objective of this study was to establish the phenotype of AT1aR-containing cells within the PVN. Accordingly, the Cre/ lox system was used to generate AT1aR-tdTomato reporter mice. An important consideration when using such an approach to localize and phenotype ATlaR-containing cells is that Crerecombinase permanently deletes the stop codon preceding tdTomato, leading to its persistent synthesis in cells that have expressed AT1aR. Plasticity in distribution of ATlaRs throughout development may confound the use of Cre/lox reporting during adulthood. That said, this approach allows for a high level of sensitivity that is not likely to be accompanied by the presence of falsely negative cells. We therefore consider this model to be an asset to the present studies, as it allows for higher sensitivity relative to our parallel RNAscope ISH control studies that yielded comparable results. Furthermore, tdTomato accurately tracked expression ATlaR in the PVN and tdTomato 
a

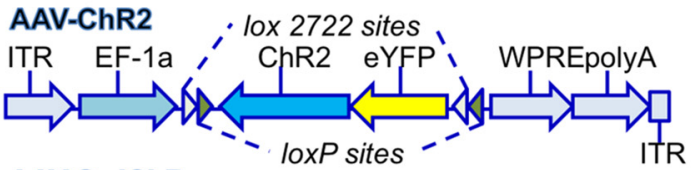

AAV-SwiChRca

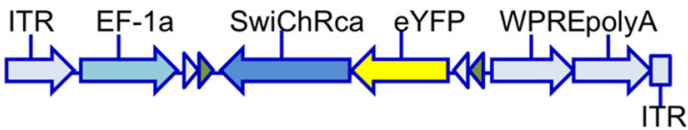

\section{AAV-CON}

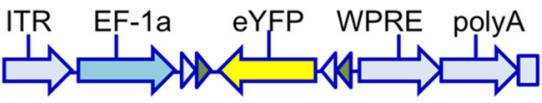

ITR
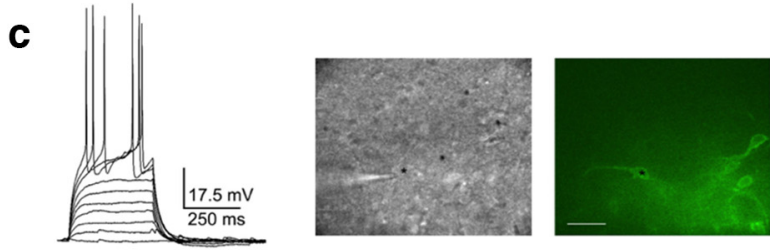

e

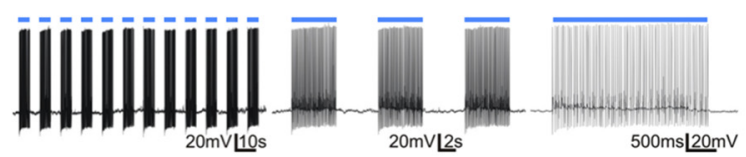

g

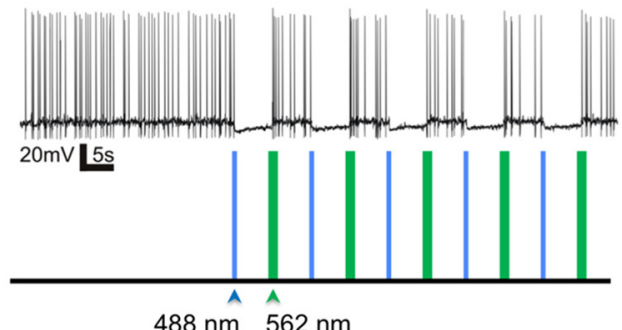

h

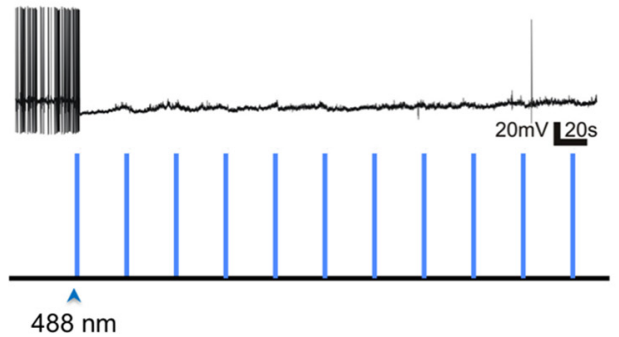

b

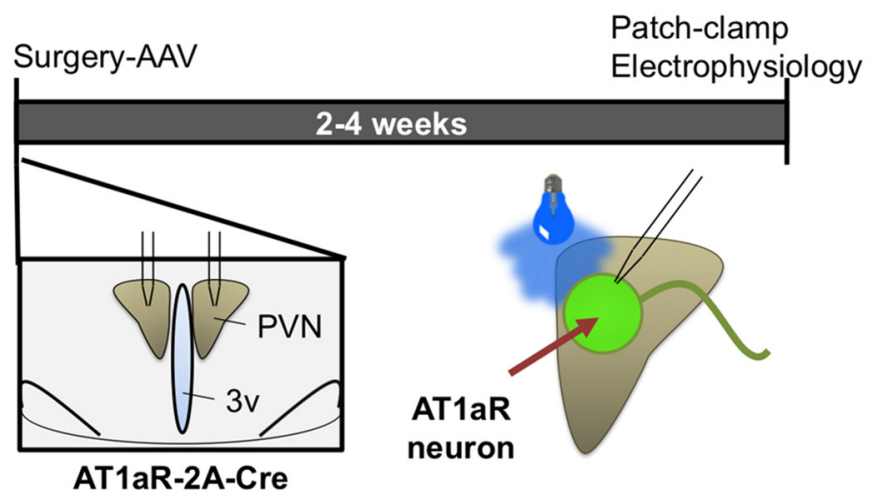

d

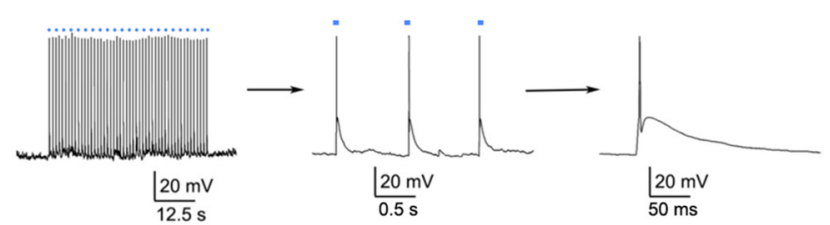

f

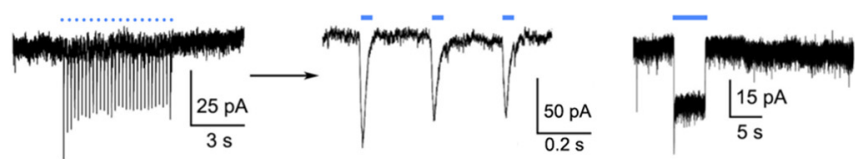

i
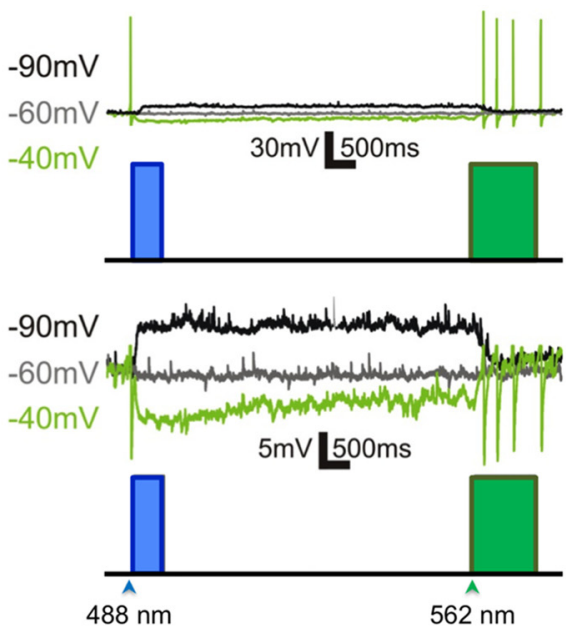

Rev Potential: $-60 \mathrm{mV}$

Figure 6. In vitro optogenetic stimulation/inhibition of PVNAT1aR neurons. $\boldsymbol{a}$, Viral constructs used for the in vitro and in vivo optogenetic studies. $\boldsymbol{b}$, Schematic of the experimental protocols used for the evaluation of the impact of optogenetic stimulation/inhibition in vitro. $c$, Left, Representative example of membrane potential changes in response to depolarizing current steps of increasing magnitude (10 pA steps) in a patched AAV-ChR2 neuron. The patched neuron was visualized using differential interference contrast (middle) and fluorescence (right) light. Asterisk indicates recorded neuron. Scale bar, $40 \mu \mathrm{m}$. $\boldsymbol{d}$, Left, Representative trace showing optogenetically evoked firing activity in the patched AAV-ChR2 neuron ( $50 \times 488 \mathrm{~nm}$ laser pulse, $2 \mathrm{~ms}$ each, $1 \mathrm{~s}$ interval). Middle, Right, Same trace is shown at a progressively expanded scale to show that each light stimulation can reproducibly evoke single action potentials in the patched neuron.e, Left, A different stimulation protocol ( $75 \times 488 \mathrm{~nm}$ laser pulse, $20 \mathrm{~ms}$ each, $67 \mathrm{~ms}$ interval, $15 \mathrm{~Hz})$ was used to evoke bursting firing in the patched AAV-ChR2 neuron. Middle, Right, The same trace is shown at a progressively expanded scale. $\boldsymbol{f}$, Left, Representative voltage-clamp trace obtained from a AAV-ChR2 neuron ( $30 \times 488 \mathrm{~nm}$ laser pulse, $10 \mathrm{~ms}$ each, $200 \mathrm{~ms}$ interval) showing reproducible evoked inward currents. Middle, Same trace is shown at a more expanded time scale. Right, A single, prolonged (5s) light stimulation pulse was given, evoking a sustained, noninactivating inward current. $\boldsymbol{g}$, Representative trace of a patched AAV-SwiChRca neuron showing that repeated brief opening ( $488 \mathrm{~nm}, 500 \mathrm{~ms}$ duration) and closing $(562 \mathrm{~nm}, 1000 \mathrm{~ms}$ duration; $5 \mathrm{~s}$ interval between opening and closing) of the chloride channels, evoked a transient inhibition of firing activity in the patched neuron. $\boldsymbol{h}$, Representative trace of a patched AAV-SwiChRca neuron showing that repeated $488 \mathrm{~nm}$ light pulses (500 ms each, every $30 \mathrm{~s}$ for $6 \mathrm{~min}$ ) nearly silenced the patched neuron for the duration of the light stimulation. $\boldsymbol{i}$, Top, Another example of a patched AAV-SwiChRca neuron in current-clamp mode showing that the changes in membrane potential evoked by opening/closing chloride channels had a reversal potential of $\sim-60 \mathrm{mV}$. For display purposes, all traces were aligned at the beginning, even though the holding potential was different. Bottom, The same traces are shown at an expanded voltage scale (action potentials were clipped) to better display changes in membrane potential. 
a

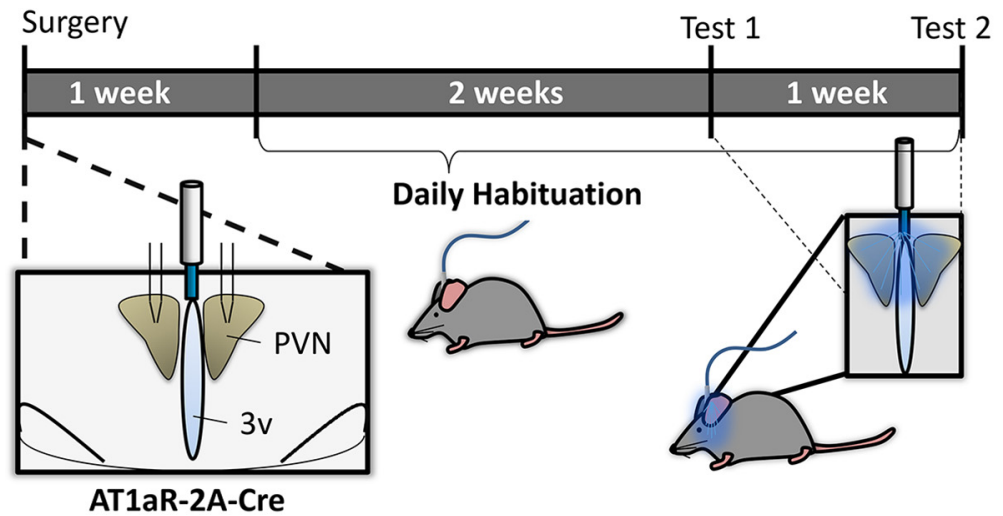

b

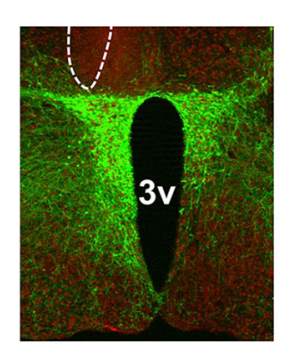

C Test

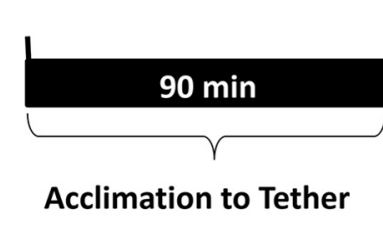

d

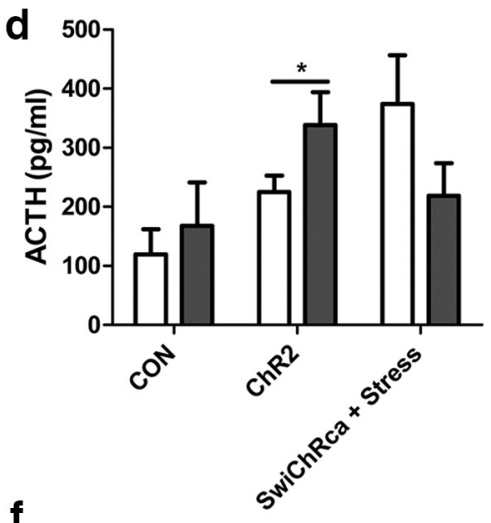

f
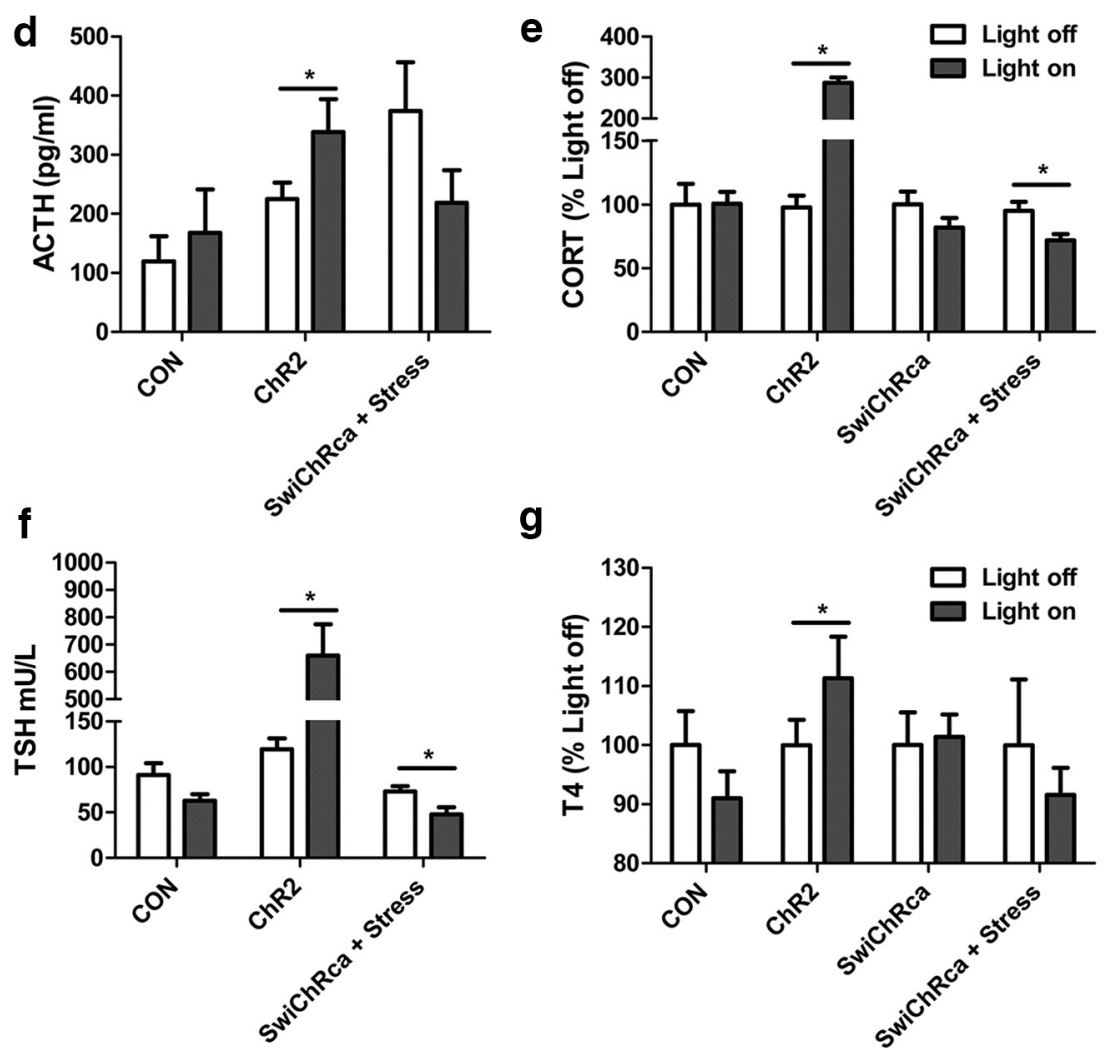

Blood Blood Collection: Collection: NO Stress STRESS

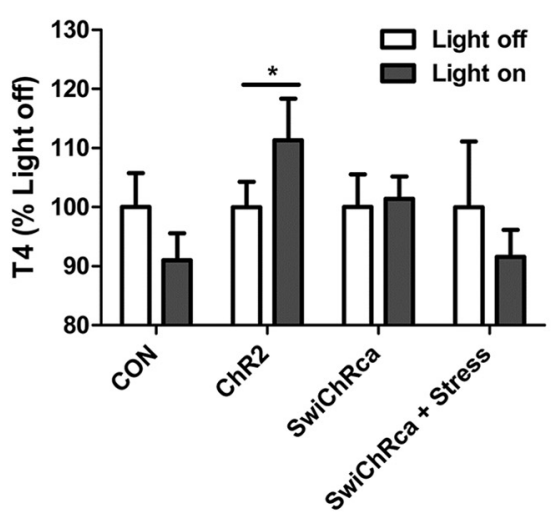

Figure 7. Impact of in vivo optogenetic stimulation/inhibition of PVN AT1aR neurons on the HPA and HPT axes. $\boldsymbol{a}$, Schematic of the experimental protocols used for the evaluation of the impact of optogenetic stimulation/inhibition on the activity of the HPA and HPT axes. Stereotaxic surgery for the injection of the AAVs described in Figure $6 a$ bilaterally into the PVN and unilateral implantation of the fiber optic post was followed by a period of recovery and habituation to the tethering protocol, and then by the test protocol. $\boldsymbol{b}$, Image of a representative hit used for these studies with eYFP in green and the neuronal marker HuC/D in red; the unilateral site of post implantation is outlined by a dashed line. $c$, The test protocol used to generate the neuroendocrine data. The blue-light stimulation/inhibition parameters are as follows: the AAV-ChR2-eYFP and the AAV-eYFP mice were subjected to 20 ms pulses, $15 \mathrm{~Hz}, 5$ s on followed by $5 \mathrm{~s}$ off; the AAV-SwiChR2 mice received $500 \mathrm{~ms}$ pulses at $0.033 \mathrm{~Hz}$; in all cases, the stimulation/ inhibition protocols continued for $15 \mathrm{~min}$. $\boldsymbol{d}-\boldsymbol{g}$, Stimulation/inhibition of AT1aR neurons using this protocol led to alterations in the circulating levels of $(\boldsymbol{d})$ ACTH, (e) CORT, (f) TSH, and $(\boldsymbol{g})$ T4. 3v, Third cerebral ventricle. Error bars indicate SEM. * $p<0.05$.

cells were excited by Ang-II, an effect that is blocked by the coadministration of an AT1R antagonist. This excitatory influence of Ang-II over PVN neurons is consistent with previously published reports (Latchford and Ferguson, 2005; de Kloet et al., 2013; Stern et al., 2016).

Subsequent to the validation of the ATlaR-tdTomato reporter mice, we ascertained that the ATlaR neurons of the PVN are glutamatergic and the majority of these neurons synthesize CRH or TRH. We determined that restraint, an acute psychogenic stressor, activates $\sim 40 \%$ of these AT1a $\mathrm{R}$-tdTomato neurons, which is strikingly similar to the percentage of PVN ATla $\mathrm{R}$-tdTomato neurons that contain $\mathrm{CRH}$ mRNA. It is tempting to speculate that the neurons activated by restraint are indeed CRH neurons. On the other hand, one may predict that a thermoregulatory stressor may shift this distribution to also activate AT1aR-positive TRH neurons. Also of relevance, no overlap was observed between ATlaR-tdTomato cells and those immunoreactive for OT or AVP, or those projecting to the ventrolateral medulla. Anterograde neuronal tract-tracing revealed that PVN ATlaR neurons send dense projections to the exterior portion of the median eminence. These results are consistent with those of Oldfield et al. (2001), who used ATlaR immunoreactivity and neuronal tract-tracing to localize AT1aRs to median eminence-projecting parvocellular neurosecretory neurons of the PVN. While studies using IHC have been scrutinized due to nonspecificity of ATlaR antibodies (Benicky et al., 2012; Herrera et al., 2013), a number of groups have come to similar conclusions (Aguilera et al., 1995; Lenkei et al., 1995, 1997; Yamamoto et al., 2011; Hurt et al., 2015; Wang et al., 2016b). That is, AT1aRs are likely localized to CRH neurons (Aguilera et al., 1995; Yamamoto et al., 2011; Hurt et al., 2015; Wang et al., 2016b) and not to magnocellular AVP or OT neurons of the PVN (Lenkei et al., 1995). That said, the absence of ATlaRs on AVP neurons may be surprising in the context of the established role of ATlaRs in the secretion of this antidiuretic hormone (Veltmar et al., 1992; Zhu et al., 2005; Littlejohn et al., 2013). Another unanticipated observation is the localization of AT1aRs to TRH neurons; a finding that brings to light the possibility that ATlaR-TRH interactions may also contribute to physiological effects exerted by the RAS.

In regards to the function of PVN ATlaR neurons, these studies are the first to interrogate their role in neuroendocrine secretion using an optogenetic ap- 
proach. Specifically, stimulation of the PVN AT1aR neurons spurs the HPT and HPA axes, while their inhibition produces the opposite effect. These findings were expected based on the neurochemical and projection phenotypes of PVN ATlaR neurons and are consistent with our previous observations that chronic intracerebroventricular administration of Ang-II elevates hypothalamic CRH and TRH mRNA (de Kloet et al., 2011). The notion that the RAS and the HPT axis may interact at the level of the PVN is novel and the implication is that one of the functions of Ang-II-activating AT1aRs residing in the PVN is to coordinate several aspects of stress-responding, including those that control metabolic rate. For example, chronic central Ang-II increases indices of brown adipose thermogenesis (de Kloet et al., 2011) and it is likely that activation of ATlaRs on TRH neurons contributes to this effect. Dysregulation of the HPT axis accompanies a number of stress-related disorders, such as depression and generalized anxiety disorder (Duval et al., 1999, 2015; Brandt et al., 2014) and it is possible that Ang-II modulation of the HPT axis contributes to the increased incidents of mental health disorders associated with overactivation of the RAS (Baghai et al., 2002, 2006; Angunsri et al., 2009; Khoury et al., 2012).

Another key finding is that optogenetic stimulation of PVN AT1aR neurons elevates systolic blood pressure. These results agree with reports that have linked PVN ATlaR activation to the regulation of cardiovascular function (Cato and Toney, 2005; de Kloet et al., 2013; Wang et al., 2016b); however, the mechanisms underlying these actions are yet to be unequivocally discerned. There is evidence for presynaptic AT1aR expression on nerve terminals within the PVN, the activation of which dampens GABAergic input to preautonomic neurons, thereby disinhibiting their activity and elevating blood pressure (Li et al., 2003; Li and Pan, 2005). Others have speculated that Ang-II directly stimulates PVN preautonomic neurons via AT1aRs localized to their soma (Cato and Toney, 2005). Finally, a recent report indicates that AT1aR activation stimulates $\mathrm{PVN}$ preautonomic neurons and renal sympathetic nerve activity via an indirect effect involving local astrocytes (Stern et al., 2016). The present studies use two separate approaches to ascertain that ATlaRs are not localized to RVLM-projecting preautonomic neurons during normotensive conditions, indicating that a direct influence over preautonomic neurons is unlikely. On the other hand, we observed an abundance of AT1aR-tdTomato nerve terminals and/or fibers within a subdivision of the PVN that contains preautonomic neurons, which may predict presynaptic control over sympathetic outflow. Nonetheless, the present study demonstrates that activation of PVN AT1aR neurons per se increases blood pressure. Therefore, the question still remains: how does this occur given that neurons in the PVN that express ATlaRs are unlikely to project to the hindbrain? One possibility is that a certain level of cross talk exists between the neurosecretory and preautonomic neurons of the parvocellular PVN that allow for the integration and coordination of responses elicited by these distinct neuronal phenotypes. Such cross talk among the various cell types of the PVN has been documented and is thought to involve the dendritic release of neuropeptides within the PVN (Son et al., 2013). Further investigation will be required to determine whether such a mechanism also underlies the blood pressure-augmenting effects associated with the firing of ATlaR neurons in the PVN.

Our studies also uncovered a role for PVN AT1aR neurons in the regulation of anxiety-like behavior. There are now several published lines of evidence indicating that the RAS plays a role in the genesis of anxiety disorders (Krause et al., 2011; Khoury et al., 2012; Marvar et al., 2014; Nylocks et al., 2015; Wang et al., 2016a,b); however, the present studies are the first to determine that the specific inhibition of the activity of these ATlaR neurons in the PVN is anxiolytic in the EPM. While these findings are consistent with those of previous studies that examined the impact of ATlaR gene deletion in PVN (Wang et al., 2016b) or in CRH neurons (Hurt et al., 2015), future studies are necessary to determine whether these anxiolytic actions are observed in alternative behavioral tests of anxiety-like behavior.

Collectively, the present study indicates that a distinct population of angiotensin-sensitive neurons serves as a key 
coordinator of the physiological responses to stress. The implication is that these ATlaRs may be targeted to alleviate stress-related disease.

\section{References}

Aguilera G, Young WS, Kiss A, Bathia A (1995) Direct regulation of hypothalamic corticotropin-releasing-hormone neurons By angiotensin-II. Neuroendocrinology 61:437-444. Medline

Angunsri R, Sritharathikhun T, Suttirat S, Tencomnao T (2009) Association of angiotensin-converting enzyme gene promoter single nucleotide polymorphisms and haplotype with major depression in a northeastern Thai population. J Renin Angiotensin Aldosterone Syst 10:179-184. CrossRef Medline

Baghai TC, Schule C, Zwanzger P, Minov C, Zill P, Ella R, Eser D, Oezer S, Bondy B, Rupprecht R (2002) Hypothalamic-pituitary-adrenocortical axis dysregulation in patients with major depression is influenced by the insertion/deletion polymorphism in the angiotensin I-converting enzyme gene. Neurosci Lett 328:299-303. CrossRef Medline

Baghai TC, Binder EB, Schule C, Salyakina D, Eser D, Lucae S, Zwanzger P, Haberger C, Zill P, Ising M, Deiml T, Uhr M, Illig T, Wichmann HE, Modell S, Nothdurfter C, Holsboer F, Müller-Myhsok B, Möller HJ, Rupprecht $\mathrm{R}$ et al. (2006) Polymorphisms in the angiotensin-converting enzyme gene are associated with unipolar depression, ACE activity and hypercortisolism. Mol Psychiatry 11:1003-1015. CrossRef Medline

Ben-Barak Y, Russell JT, Whitnall MH, Ozato K, Gainer H (1985) Neurophysin in the hypothalamo-neurohypophysial system. I. Production and characterization of monoclonal antibodies. J Neurosci 5:81-97. Medline

Benicky J, Hafko R, Sanchez-Lemus E, Aguilera G, Saavedra JM (2012) Six commercially available angiotensin II AT1 receptor antibodies are nonspecific. Cell Mol Neurobiol 32:1353-1365. CrossRef Medline

Biancardi VC, Stranahan AM, Krause EG, de Kloet AD, Stern JE (2016) Cross talk between AT1 receptors and Toll-like receptor 4 in microglia contributes to angiotensin II-derived ROS production in the hypothalamic paraventricular nucleus. Am J Physiol Heart Circ Physiol 310: H404-H415. CrossRef Medline

Brandt F, Thvilum M, Almind D, Christensen K, Green A, Hegedüs L, Brix TH (2014) Hyperthyroidism and psychiatric morbidity: evidence from a Danish nationwide register study. Eur J Endocrinol 170:341348. CrossRef Medline

Cato MJ, Toney GM (2005) Angiotensin II excites paraventricular nucleus neurons that innervate the rostral ventrolateral medulla: an in vitro patch-clamp study in brain slices. J Neurophysiol 93:403-413. Medline

de Kloet AD, Krause EG, Kim DH, Sakai RR, Seeley RJ, Woods SC (2009) The effect of angiotensin-converting enzyme inhibition using captopril on energy balance and glucose homeostasis. Endocrinology 150:41144123. CrossRef Medline

de Kloet AD, Krause EG, Scott KA, Foster MT, Herman JP, Sakai RR, Seeley RJ, Woods SC (2011) Central angiotensin II has catabolic action at white and brown adipose tissue. Am J Physiol Endocrinol Metab 301:E1081E1091. CrossRef Medline

de Kloet AD, Pati D, Wang L, Hiller H, Sumners C, Frazier CJ, Seeley RJ, Herman JP, Woods SC, Krause EG (2013) Angiotensin type la receptors in the paraventricular nucleus of the hypothalamus protect against dietinduced obesity. J Neurosci 33:4825-4833. CrossRef Medline

de Kloet AD, Wang L, Ludin JA, Smith JA, Pioquinto DJ, Hiller H, Steckelings UM, Scheuer DA, Sumners C, Krause EG (2016) Reporter mouse strain provides a novel look at angiotensin type-2 receptor distribution in the central nervous system. Brain Struct Funct 221:891-912. CrossRef Medline

Dimitrov EL, Yanagawa Y, Usdin TB (2013) Forebrain GABAergic projections to locus coeruleus in mouse. J Comp Neurol 521:2373-2397. CrossRef Medline

Duval F, Mokrani MC, Bailey P, Correa H, Diep TS, Crocq MA, Macher JP (1999) Thyroid axis activity and serotonin function in major depressive episode. Psychoneuroendocrinology 24:695-712. CrossRef Medline

Duval F, Mokrani MC, Erb A, Gonzalez Lopera F, Alexa C, Proudnikova X, Butucaru I (2015) Chronobiological hypothalamic-pituitary-thyroid axis status and antidepressant outcome in major depression. Psychoneuroendocrinology 59:71-80. CrossRef Medline

Franklin KBJ, Paxinos G (2008) The mouse brain: in stereotaxic coordinates, 3rd edition. New York: Elsevier.

Häuser W, JöhrenO, Saavedra JM (1998) Characterization and distribution of angiotensin II receptor subtypes in the mouse brain. Eur J pharmacol 348:101-114. CrossRef Medline
Herrera M, Sparks MA, Alfonso-Pecchio AR, Harrison-Bernard LM, Coffman TM (2013) Lack of specificity of commercial antibodies leads to misidentification of angiotensin type 1 receptor protein. Hypertension 61:253-258. CrossRef Medline

Hrabovszky E, Wittmann G, Turi GF, Liposits Z, Fekete C (2005) Hypophysiotropic thyrotropin-releasing hormone and corticotropin-releasing hormone neurons of the rat contain vesicular glutamate transporter-2. Endocrinology 146:341-347. CrossRef Medline

Hurt RC, Garrett JC, Keifer OP Jr, Linares A, Couling L, Speth RC, Ressler KJ, Marvar PJ (2015) Angiotensin type la receptors on corticotropinreleasing factor neurons contribute to the expression of conditioned fear. Genes Brain Behav 14:526-533. CrossRef Medline

Isegawa K, Hirooka Y, Katsuki M, Kishi T, Sunagawa K (2014) Angiotensin II type 1 receptor expression in astrocytes is upregulated leading to increased mortality in mice with myocardial infarction-induced heart failure. Am J Physiol Heart Circ Physiol 307:H1448-H1455. CrossRef Medline

Jasper MS, Engeland WC (1991) Synchronous ultradian rhythms in adrenocortical secretion detected by microdialysis in awake rats. Am J Physiol 261:R1257-R1268. Medline

Jessberger S, Toni N, Clemenson GD Jr, Ray J, Gage FH (2008) Directed differentiation of hippocampal stem/progenitor cells in the adult brain. Nat Neurosci 11:888-893. CrossRef Medline

Kádár A, Sánchez E, Wittmann G, Singru PS, Füzesi T, Marsili A, Larsen PR, Liposits Z, Lechan RM, Fekete C (2010) Distribution of hypophysiotropic thyrotropin-releasing hormone (TRH)-synthesizing neurons in the hypothalamic paraventricular nucleus of the mouse. J Comp Neurol 518: 3948-3961. CrossRef Medline

Khoury NM, Marvar PJ, Gillespie CF, Wingo A, Schwartz A, Bradley B, Kramer M, Ressler KJ (2012) The renin-angiotensin pathway in posttraumatic stress disorder: angiotensin-converting enzyme inhibitors and angiotensin receptor blockers are associated with fewer traumatic stress symptoms. J Clin Psychiatry 73:849-855. CrossRef Medline

Krause EG, Melhorn SJ, Davis JF, Scott KA, Ma LY, de Kloet AD, Benoit SC, Woods SC, Sakai RR (2008) Angiotensin type 1 receptors in the subfornical organ mediate the drinking and hypothalamic-pituitaryadrenal response to systemic isoproterenol. Endocrinology 149:64166424. CrossRef Medline

Krause EG, de Kloet AD, Scott KA, Flak JN, Jones K, Smeltzer MD, Ulrich-Lai YM, Woods SC, Wilson SP, Reagan LP, Herman JP, Sakai RR (2011) Blood-borne angiotensin II acts in the brain to influence behavioral and endocrine responses to psychogenic stress. J Neurosci 31:15009-15015. CrossRef Medline

Latchford KJ, Ferguson AV (2005) Angiotensin depolarizes parvocellular neurons in paraventricular nucleus through modulation of putative nonselective cationic and potassium conductances. Am J Physiol Regul Integr Comp Physiol 289:R52-R58. CrossRef Medline

Lenkei Z, Corvol P, Llorens-Cortes C (1995) Comparative expression of vasopressin and angiotensin type- 1 receptor mRNA in rat hypothalamic nuclei: a double in situ hybridization study. Brain Res Mol Brain Res 34:135-142. CrossRef Medline

Lenkei Z, Palkovits M, Corvol P, Llorens-Cortès C (1997) Expression of angiotensin type-1 (AT1) and type-2 (AT2) receptor mRNAs in the adult rat brain: a functional neuroanatomical review. Front Neuroendocrinol 18:383-439. CrossRef Medline

Li DP, Pan HL (2005) Angiotensin II attenuates synaptic GABA release and excites paraventricular-rostral ventrolateral medulla output neurons. J Pharmacol Exp Ther 313:1035-1045. CrossRef Medline

Li DP, Chen SR, Pan HL (2003) Angiotensin II stimulates spinally projecting paraventricular neurons through presynaptic disinhibition. J Neurosci 23:5041-5049. Medline

Littlejohn NK, Siel RB Jr, Ketsawatsomkron P, Pelham CJ, Pearson NA, Hilzendeger AM, Buehrer BA, Weidemann BJ, Li H, Davis DR, Thompson AP, Liu X, Cassell MD, Sigmund CD, Grobe JL (2013) Hypertension in mice with transgenic activation of the brain renin-angiotensin system is vasopressin dependent. Am J Physiol Regul Integr Comp Physiol 304: R818-R828. CrossRef Medline

Luther JA, Tasker JG (2000) Voltage-gated currents distinguish parvocellular from magnocellular neurones in the rat hypothalamic paraventricular nucleus. J Physiol 523:193-209. CrossRef Medline

Luther JA, Daftary SS, Boudaba C, Gould GC, Halmos KC, Tasker JG (2002) Neurosecretory and non-neurosecretory parvocellular neurones of the 
hypothalamic paraventricular nucleus express distinct electrophysiological properties. J Neuroendocrinol 14:929-932. CrossRef Medline

Marvar PJ, Goodman J, Fuchs S, Choi DC, Banerjee S, Ressler KJ (2014) Angiotensin type 1 receptor inhibition enhances the extinction of fear memory. Biol Psychiatry 75:864-872. CrossRef Medline

Nylocks KM, Michopoulos V, Rothbaum AO, Almli L, Gillespie CF, Wingo A, Schwartz AC, Habib L, Gamwell KL, Marvar PJ, Bradley B, Ressler KJ (2015) An angiotensin-converting enzyme (ACE) polymorphism may mitigate the effects of angiotensin-pathway medications on posttraumatic stress symptoms. Am J Med Genet B Neuropsychiatr Genet 168B: 307-315. CrossRef Medline

Oldfield BJ, Davern PJ, Giles ME, Allen AM, Badoer E, McKinley MJ (2001) Efferent neural projections of angiotensin receptor (AT1) expressing neurones in the hypothalamic paraventricular nucleus of the rat. J Neuroendocrinol 13:139-146. CrossRef Medline

Pavlatou MG, Mastorakos G, Lekakis I, Liatis S, Vamvakou G, Zoumakis E, Papassotiriou I, Rabavilas AD, Katsilambros N, Chrousos GP (2008) Chronic administration of an angiotensin II receptor antagonist resets the hypothalamic-pituitary-adrenal (HPA) axis and improves the affect of patients with diabetes mellitus type 2: preliminary results. Stress 11:6272. CrossRef Medline

Pohlenz J, Maqueem A, Cua K, Weiss RE, Van Sande J, Refetoff S (1999) Improved radioimmunoassay for measurement of mouse thyrotropin in serum: strain differences in thyrotropin concentration and thyrotroph sensitivity to thyroid hormone. Thyroid 9:1265-1271. CrossRef Medline

Potapenko ES, Biancardi VC, Florschutz RM, Ryu PD, Stern JE (2011) Inhibitory-excitatory synaptic balance is shifted toward increased excitation in magnocellular neurosecretory cells of heart failure rats. J Neurophysiol 106:1545-1557. CrossRef Medline

Saavedra JM (2012) Angiotensin II AT(1) receptor blockers ameliorate inflammatory stress: a beneficial effect for the treatment of brain disorders. Cell Mol Neurobiol 32:667-681. CrossRef Medline

Saavedra JM, Sánchez-Lemus E, Benicky J (2011) Blockade of brain angiotensin II AT1 receptors ameliorates stress, anxiety, brain inflammation and ischemia: therapeutic implications. Psychoneuroendocrinology 36: 1-18. CrossRef Medline

Son SJ, Filosa JA, Potapenko ES, Biancardi VC, Zheng H, Patel KP, Tobin VA,
Ludwig M, Stern JE (2013) Dendritic peptide release mediates interpopulation crosstalk between neurosecretory and preautonomic networks. Neuron 78:1036-1049. CrossRef Medline

Stern JE (2001) Electrophysiological and morphological properties of preautonomic neurones in the rat hypothalamic paraventricular nucleus. J Physiol 537:161-177. CrossRef Medline

Stern JE, Son S, Biancardi VC, Zheng H, Sharma N, Patel KP (2016) Astrocytes contribute to angiotensin II stimulation of hypothalamic neuronal activity and sympathetic outflow. Hypertension 68:1483-1493. CrossRef Medline

Sun H, Wu H, Yu X, Zhang G, Zhang R, Zhan S, Wang H, Bu N, Ma X, Li Y (2015) Angiotensin II and its receptor in activated microglia enhanced neuronal loss and cognitive impairment following pilocarpine-induced status epilepticus. Mol Cell Neurosci 65:58-67. CrossRef Medline

Veltmar A, Culman J, Qadri F, Rascher W, Unger T (1992) Involvement of adrenergic and angiotensinergic receptors in the paraventricular nucleus in the angiotensin II-induced vasopressin release. J Pharmacol Exp Ther 263:1253-1260. Medline

Wang L, de Kloet AD, Pati D, Hiller H, Smith JA, Pioquinto DJ, Ludin JA, Oh SP, Katovich MJ, Frazier CJ, Raizada MK, Krause EG (2016a) Increasing brain angiotensin converting enzyme 2 activity decreases anxiety-like behavior in male mice by activating central Mas receptors. Neuropharmacology 105:114-123. CrossRef Medline

Wang L, Hiller H, Smith JA, de Kloet AD, Krause EG (2016b) Angiotensin type 1a receptors in the paraventricular nucleus of the hypothalamus control cardiovascular reactivity and anxiety-like behavior in male mice. Physiol Genomics 48:667-676. CrossRef Medline

Yamamoto R, Akazawa H, Fujihara H, Ozasa Y, Yasuda N, Ito K, Kudo Y, Qin Y, Ueta Y, Komuro I (2011) Angiotensin II type 1 receptor signaling regulates feeding behavior through anorexigenic corticotropin-releasing hormone in hypothalamus. J Biol Chem 286:21458-21465. CrossRef Medline

Zhu Q, Guo SY, Gong S, Yin QZ, Hisamitsu T, Jiang XH (2005) Losartan blocks the excitatory effect of peripheral hypertonic stimulation on vasopressinergic neurons in hypothalamic paraventricular nucleus in rats: electrophysiological and immunocytochemical evidence. Neurosci Lett 380:12-16. CrossRef Medline 